\title{
Vivienda y patrimonio industrial: los campamentos del petróleo en Magallanes
}

\author{
Housing and Industrial Heritage: \\ The Oil 's Camps in Magallanes
Dr. Boris Cvitanic Díaz ${ }^{a}$ Dr. Daniel Matus Carrasco ${ }^{a}$
aAcadémico Universidad de Magallanes, Chile.
boris.cvitanic@umag.cl [orcid.org/0000-0002-9008-6519]
daniel.matus@umag.cl [orcid.org/0000-0002-7066-9610]

\begin{abstract}
RESUMEN
El descubrimiento de petróleo en la región de Magallanes detonó la aparición de infraestructuras y asentamientos humanos para la exploración, explotación, refinación y transporte de la producción. La historiografía local ha resaltado parcialmente el valor arquitectónico, paisajístico, histórico y social de un proceso singular de industrialización, dejando de lado las particularidades del hábitat colectivo asociado a la industria petrolera en la región austral. Este trabajo presenta la arquitectura de la vivienda de los campamentos del petróleo como una dimensión relevante en la construcción del patrimonio industrial asociado a la actividad petrolera de la región de Magallanes entre 1945 y 1972.
\end{abstract}

PALABRAS CLAVE: arquitectura residencial, región de Magallanes, hábitat colectivo, ENAP.

\begin{abstract}
The discovery of oil in the Magallanes Region triggered the emergence of infrastructure and human settlements for exploration, exploitation, refining and transportation of its production. Local historiography has partially highlighted the architectural, landscape, historical and social value of this phenomenon, leaving aside the particularities of collective housing associated with the oil industry Chile's southernmost region. This paper presents the architecture of the oil's camps housing as a relevant dimension in the construction of industrial heritage associated with the oil industry between 1945 and 1972 in the Magallanes Region.
\end{abstract}


KEY WORDS: Residential architecture, Region of Magallanes, Collective housing, ENAP.

\section{INTRODUCCIÓN}

La puesta en marcha de la industria de los hidrocarburos por parte del Estado chileno desde 1931 (Ley Nº4.927 del 7 de enero de 1931) requirió de la elaboración de una extensa y compleja planificación, condicionada, por un lado, por la existencia de campos de petróleo explotables y, por otro lado, por la disponibilidad de una precaria red de caminos e infraestructuras en zonas diversas del espacio geográfico nacional. A partir de 1939, el Estado, por medio de la Corporación de Fomento (CORFO) se abocó a la exploración y explotación del petróleo, descubierto en el sector norte de la Isla Grande de Tierra del Fuego el 29 de diciembre de 1945, actividad industrial que prosiguió desde 1950 bajo la responsabilidad de la Empresa Nacional del Petróleo (ENAP), creada para tales efectos, hasta su transformación en una empresa matriz y cuatro empresas filiales en 1981 (ENAP, 1982a, p. 1).

A partir del descubrimiento de los hidrocarburos se hizo necesario volver operativa y rentable la producción, así como también industrializarla, comercializarla y distribuirla, mientras nuevos campos explotables eran prospectados en forma paralela, lo que a través del tiempo fue definiendo, con una complejidad creciente, una serie de territorios del petróleo primero en la región de Magallanes, y más tarde en las regiones de Valparaíso y Biobío, e involucraron finalmente prácticamente la totalidad del territorio nacional (Matus \& Cvitanic, 2018, p. 136).

Para lograr llevar a cabo su cometido, definido en el marco normativo en cuanto a la explotación de hidrocarburos (Ley No 9.618, del 19 de junio de 1950), la empresa estatal emprendió la construcción de terminales marítimos y terrestres, plantas, caminos, edificios de logística y de administración en gran parte del territorio chileno (Fig. 1). Infraestructuras que se levantaron, en la mayoría de las ocasiones, con independencia de los asentamientos humanos y de las redes productivas existentes.

Particularmente, en la región de Magallanes, la construcción, puesta en marcha y operación de la industria petrolera y de sus infraestructuras requirió, de parte de la empresa estatal, disponer de mano de obra en los lugares de producción. Se constituyó así una serie de asentamientos, pertenecientes a un sistema de mayor complejidad, destinados a implantar en el territorio todos los elementos e infraestructuras necesarias para la actividad productiva, con un particular énfasis en fijar in situ la mano de obra especializada, lo que obligó a urbanizar y a construir equipamientos colectivos y residencia para sus trabajadores, expresada en diversos modelos de vivienda para empleados y obreros, solteros y con familia. Se consolidó así una red de siete asentamientos: Manantiales (1953-1978), Percy (1957-2011), Clarencia (19512011), Cerro Sombrero (1958-), Cullen (1960-), Gregorio (1962-) y Posesión (1962-); los que conformaron una de las expresiones más visibles y conocidas de la labor productiva que ha desarrollado, y aún desarrolla, el Estado chileno en la región de Magallanes (Fig. 2). 


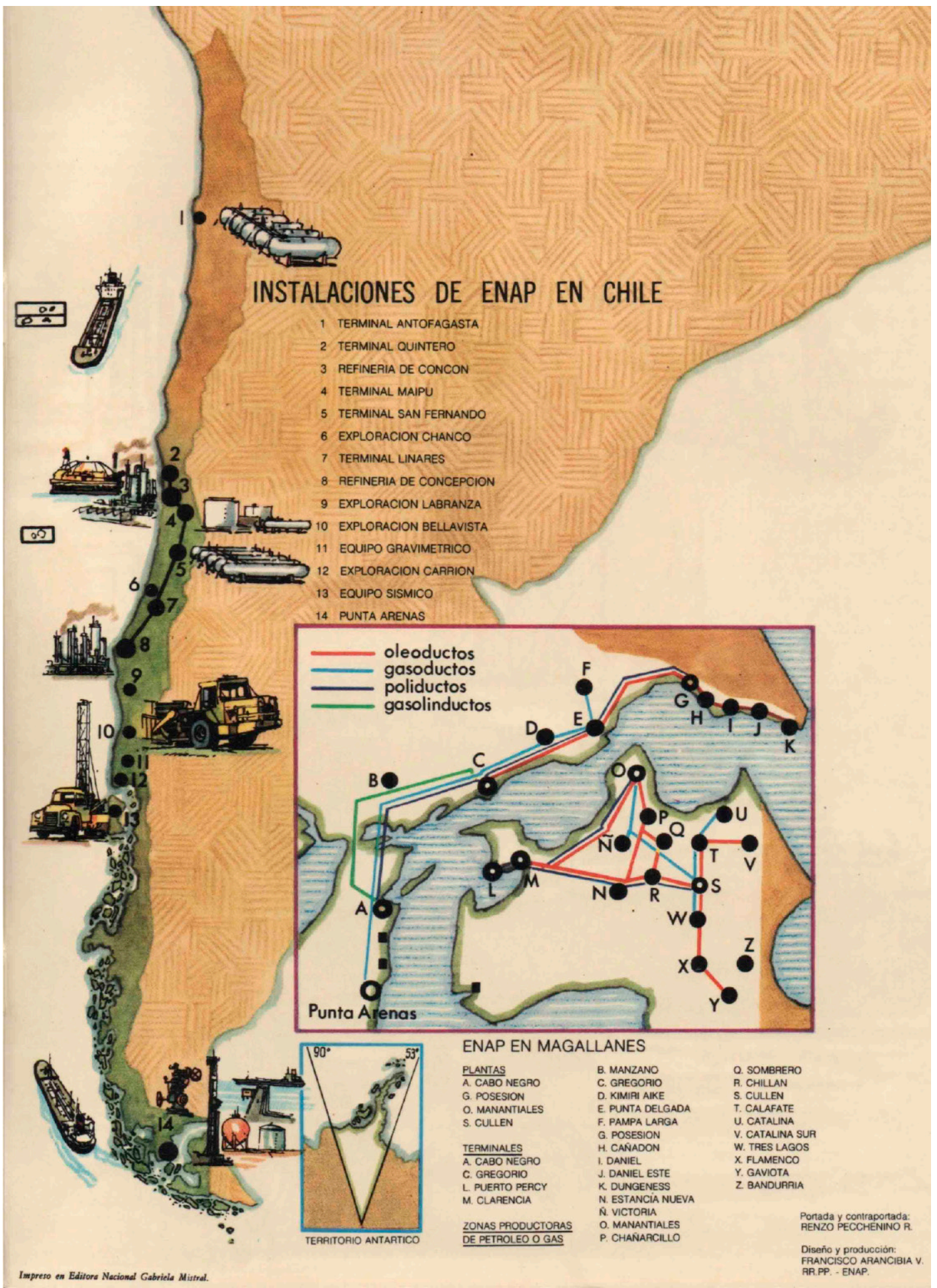

Fig. 1. Mapa de instalaciones de la ENAP en el país.

Fuente: ENAP (1976). 


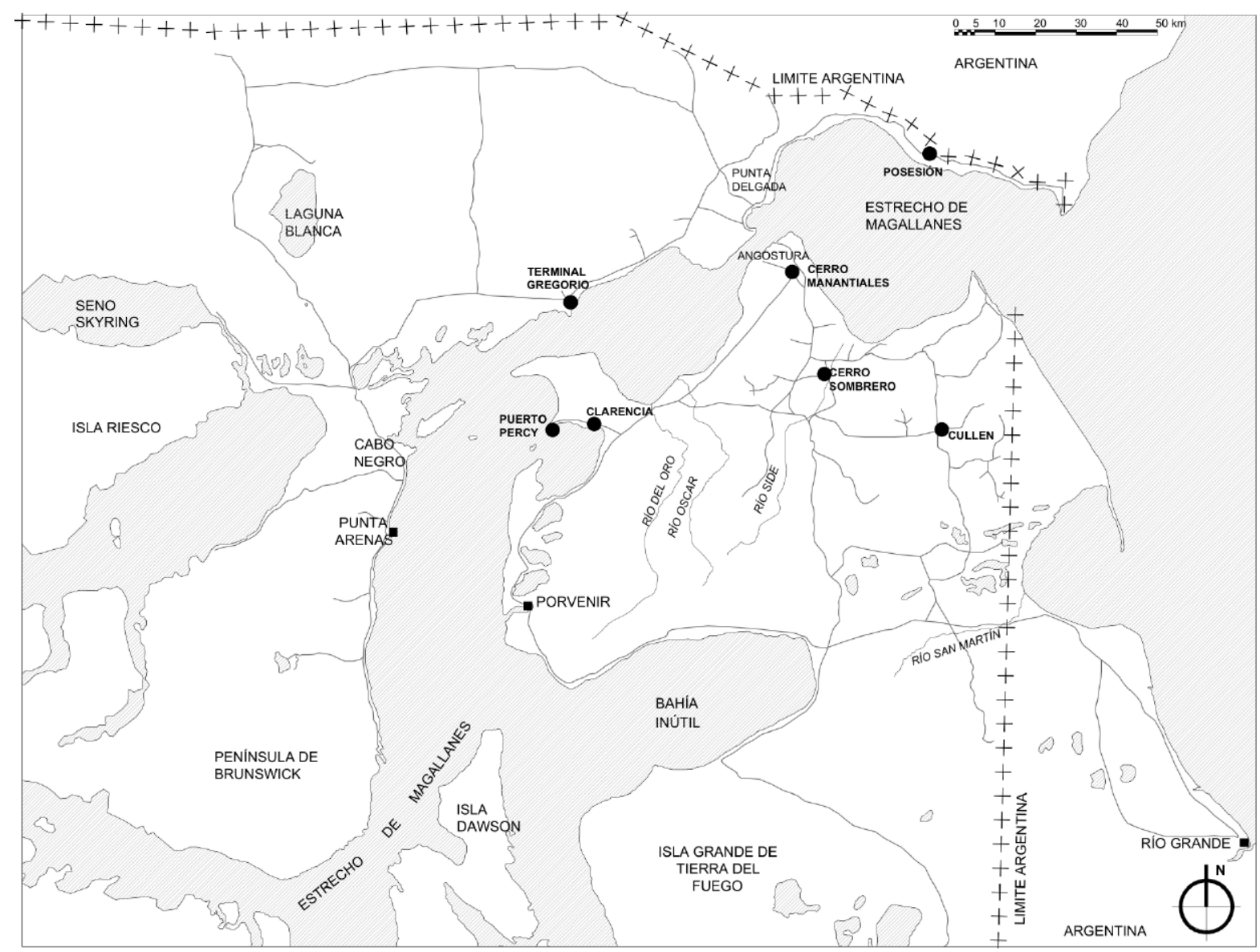

Fig. 2. Campamentos petroleros en la región de Magallanes y Antártica Chilena. Fuente: Elaboración de los autores. Dibujo: Carolina Márquez C.

El proceso industrial relacionado con la extracción, refinación, almacenamiento, transporte y distribución del petróleo, así como del gas y sus subproductos, requirió tanto de un soporte técnico y tecnológico, como de un contingente de obreros y empleados altamente especializados. Efectivamente, al crecer la demanda de la industria, el número de trabajadores contratados mutó radicalmente. Así, de los 91 trabajadores contratados en la región de Magallanes en 1943 (12 empleados y 79 obreros) se pasó a 795 en 1950 (125 empleados y 670 obreros) (ENAP, 1951), 2.343 en 1960 (775 empleados y 1.568 obreros) (ENAP, 1961c), 2.151 en 1970 (1.184 empleados y 967 obreros) (ENAP, 1971), totalizando 2.390 en $1980^{1}$ (ENAP, 1981). La necesidad del Estado por fijar la mano de obra especializada para el desarrollo de la industria petrolera determinó la institucionalización de una respuesta que, en la forma de asentamientos permanentes, permitió la residencia de empleados y obreros en las mismas zonas de producción, y que a poco andar fue complementado con un Plan Habitacional para

El cambio legal implicado en el Decreto Ley №2.200 de 1978 produjo una transformación en la normativa laboral, suprimiendo las categorías obrero y empleado, sustituyéndolas por la categoría trabajador. 
otorgar vivienda en propiedad a sus funcionarios, preferentemente en la misma región de sus actividades laborales (Matus \& Cvitanic, 2016) ${ }^{2}$.

En los territorios de explotación, los denominados campamentos petroleros incorporaron equipamientos como escuelas, postas de salud, cines, gimnasios, cooperativas, casinos, parroquias católicas, plazas y espacios de juego, entre otros; intentando, en diferente medida, constituirse en centros de vida urbana (Cvitanic, Matus, Ambrosetti, Herrera \& Bustos, 2018, p. 99). Sin embargo, el verdadero soporte de la industrialización emergente fue la vivienda destinada a los obreros y empleados de la ENAP, más aún, el arribo progresivo de grupos familiares a vivir al hábitat colectivo creado, motivó, dio sentido y estableció la dimensión y envergadura de los equipamientos construidos (Fig. 3).

Siendo así, es interesante destacar que las expresiones materiales asociadas a la industria petrolera han gozado de desigual atención en la historiografía local. Mientras algunos autores han hecho ver el valor arquitectónico de ciertos elementos, como las plataformas petroleras (Puga, 1991) o el campamento de Cerro Sombrero (Hecht, 2002, 2005; Domínguez, 2011), otros autores han abordado aspectos paisajísticos (Garcés et al. 2013), históricos (Martinic, 1988, 2005, 2006, 2009; Fugellie, 1995) y sociales (Acevedo \& Rojas, 2015) del proceso industrial, enfocándose principalmente en las dimensiones productivas, estéticas y territoriales de sus expresiones materiales. En general, la historiografía en Magallanes ha dejado de lado la dimensión habitacional de los asentamientos productivos, invisibilizando una de las expresiones fundamentales en la constitución de la actividad industrial, y con ello del patrimonio industrial (Bergeron, 1995).

En efecto, la declaración de Monumentos Nacionales (Ministerio de Educación, 2014), en la categoría de "Monumento Histórico" para edificaciones del campamento de Cerro Sombrero, se enfocó principalmente en las obras singulares, como el Surtidor de gasolina, o en algunos edificios de equipamientos de cierto interés formal del denominado Centro Cívico. Por su parte, la declaración de "Zona Típica o Pintoresca” (Ministerio de Educación, 2014) del mismo campamento, si bien incluyó los conjuntos de viviendas, se basó en información incompleta que no da cuenta de las modalidades de residencia y de sus variaciones ${ }^{3}$.

Hemos partido de la idea que la vivienda de los campamentos petroleros es una pieza central de la constitución de un hábitat colectivo que amerita, por su inscripción territorial e histórica, una mirada más atenta enfocada a partir de los conceptos de patrimonio industrial y que, metodológicamente, recurre al análisis de insumos materiales legados por la industria de los hidrocarburos, relativos tanto a su modo de producción como a sus formas de gestión

2 Entre la década de 1950 y el año 1984 los trabajadores de la empresa construyeron 665 viviendas en 12 operaciones habitacionales de distinta envergadura, gestionadas por medio del Plan Habitacional de la ENAP en Magallanes. Además se debe considerar un número indeterminado de operaciones individuales de los trabajadores de la empresa, localizadas mayoritariamente en la ciudad de Punta Arenas.

3 La declaratoria señala un modelo de vivienda para empleados cuando efectivamente se trata de dos modelos de distinta envergadura. A su vez indica la existencia de siete viviendas aisladas para obreros, cuando se trata de pabellones colectivos de dormitorios. Finalmente, en la memoria de la declaratoria fueron obviados los pabellones colectivos de dormitorios para empleados y choferes (Matus y Cvitanic, 2018, p. 138). 


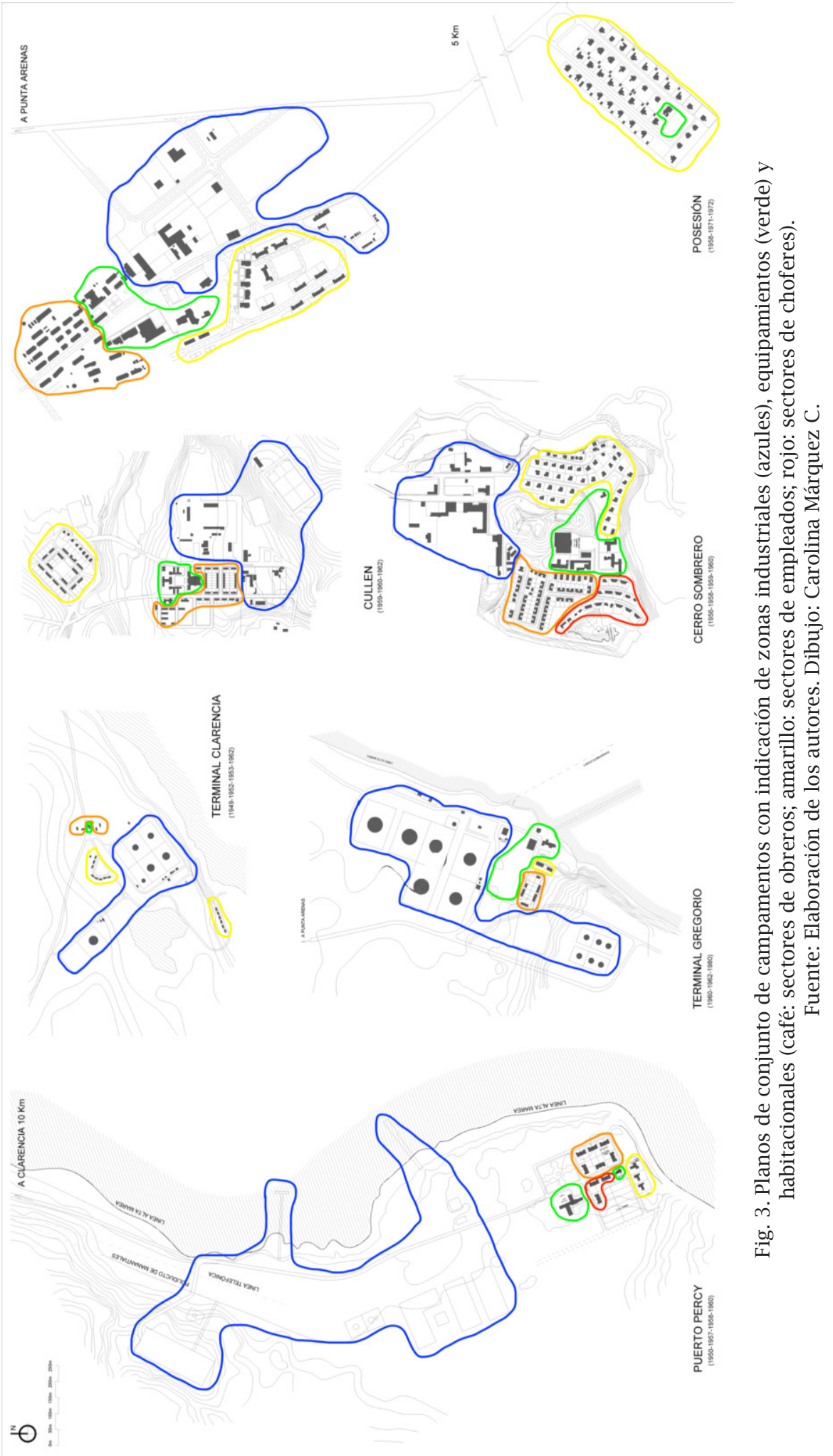


del espacio y la mano de obra. En este sentido, una vez identificados los asentamientos humanos permanentes de la actividad petrolera, se recurrió a fuentes primarias presentes en los archivos de la Empresa Nacional del Petróleo, de la Dirección de Obras Municipales de la I. Municipalidad de Punta Arenas y del Archivo Nacional, en busca de los antecedentes documentales y planimétricos originales de las obras realizadas. Posteriormente, se efectuaron levantamientos en terreno que permitieron ratificar los antecedentes documentales. Finalmente, se abordó un trabajo de revisión de las fuentes bibliográficas dedicadas a la temática. De este modo, el cruce de las tres aproximaciones llevadas a cabo permitió contrastar la información histórica, de archivo y las materializaciones implementadas, las que permitieron abordar los supuestos de inicio, interpretar la problemática planteada y afinar las reflexiones finales.

En términos temporales, el presente trabajo se circunscribió, por un lado, al inicio de la actividad extractiva en 1945, y, por otro, al último registro de construcción de viviendas en campamentos por parte de la empresa, realizado en 1972.

\section{Patrimonio Industrial y Vivienda}

La irrupción del concepto de patrimonio industrial corresponde a un proceso de reciente gestación (Álvarez-Areces, 2008; Pizzi, Valenzuela \& Benavides, 2009; Pardo, 2016; Brito, Cerda, Fuentes \& Pérez, 2018), que surge y transita a partir de la estabilización del concepto de arqueología industrial durante la década de 1960 en Inglaterra, en particular a través de las publicaciones de Kenneth Hudson y Michael Rix (Labadi, 2001; Chassagne, 2002; Pizzi et al. 2009). Si en Inglaterra Buchanan definía a la arqueología industrial como el estudio e investigación de los restos del pasado industrial (Pizzi et al. 2009, p. 31), en Francia, Woronoff la definía como el estudio "de la relación entre producción y lugar de producción" (1989, p. 447) inscrita en un campo de investigación de aproximaciones históricas, más que en una disciplina nueva. Más aún, para Françoise Choay "a diferencia de la arqueología clásica, la arqueología industrial nació de la voluntad de protección a la que continúa siendo fiel" (Merlin \& Choay, 2005, p. 62), siendo justamente el énfasis puesto en la conservación de elementos con altas probabilidades de ser destruidos y desaparecer lo que emparenta la arqueología industrial y el patrimonio industrial. El tránsito que operó entre un concepto y otro ha determinado similitudes y diferencias, la inclusión o exclusión de períodos históricos disímiles; además, en el caso del patrimonio industrial, la emergencia de escuelas que participan de diferentes enfoques (Pizzi et al. 2009, p. 34) .

4 Según estos autores, en cuanto a su dimensión arquitectónica, se identifican cuatro líneas de pensamiento en términos del abordaje del patrimonio industrial: la Escuela Inglesa, con orientación hacia los restos materiales de la industria; la Escuela Italiana, los aspectos materiales y la sociedad capitalista; la Escuela Francesa, con enfoque en "el mundo moderno y contemporáneo fabricado por el hombre" (p. 34); y la Escuela Española, centrada en la Revolución Industrial a partir de fines del siglo XVIII. 
Ahora bien, el patrimonio industrial ha seguido similar proceso al de la noción general de patrimonio, en cuanto a los cambios de visión e interpretación de los monumentos y de los objetos de valor en el transcurso del siglo XX (Choay, 2007; Babelon \& Chastel, 2013; Ibarra, 2015); si en su dimensión material discurrió desde un interés por los elementos singulares y excepcionales hacia interpretaciones de los conjuntos, los paisajes industriales y los sistemas y redes industriales (Pardo, 2016), en su dimensión inmaterial el patrimonio incluyó los modos de producción y sus resultados, las derivaciones del proceso industrial, la memoria de los diversos grupos colectivos involucrados, sus testimonios y sus formas de vida, en síntesis, los “agentes que protagonizan la extracción, producción y reproducción en las sociedades industriales y sus culturas del trabajo” (Brito et al. 2018, p. 9).

A este respecto, la Carta de Nizhny Tagil de 2003 sobre el patrimonio industrial fue explícita en términos de englobar en la definición del patrimonio industrial, no sólo los “edificios y maquinaria, talleres, molinos y fábricas, minas y sitios para procesar y refinar, almacenes y depósitos, lugares donde se genera, se transmite y se usa energía, medios de transporte y toda su infraestructura”, sino que también los entornos relacionados con la industria "como la vivienda, el culto religioso o la educación” (TICCIH, 2003, p. 1). En este sentido, Dorel-Ferré (2008) ha hecho hincapié específicamente en la relevancia del hábitat obrero, en cuanto a que:

La presencia del hábitat posee una doble dimensión explicativa: por un lado, es testimonio del asentamiento de la gente en un lugar concreto, alrededor de recursos, de vías de comunicación o de una fuente energética, y, por otra parte, como hábitat obrero diferenciado, define a la industria en sí misma. Es evidente: hay industria allí donde hay un hábitat obrero" (p. 9).

La aparición, desarrollo y perfeccionamiento de la dimensión residencial involucrada con la actividad industrial evidencia la necesidad de la acumulación de la fuerza de trabajo y la retención de los trabajadores, recurriendo en la mayoría de los casos también al grupo familiar del trabajador, con sus propias necesidades y requerimientos. La búsqueda de la máxima productividad, o la búsqueda de una mejora en las condiciones laborales, determinó la configuración de un "espacio de orden" por parte de la empresa (Bergeron, 1995), donde la residencia, y particularmente la vivienda, se constituyó en el dispositivo central.

En la región de Magallanes las investigaciones sobre patrimonio industrial son recientes y han sido abordadas de un modo panorámico, tanto los asentamientos productivos de fines del siglo XIX hasta la década de 1970, originados a partir de la ganadería ovina en extensión (Cvitanic \& Matus, 2018), así como también los campamentos petroleros de la isla de Tierra del Fuego (Acevedo \& Rojas, 2014; Cvitanic, Matus, Ambrosetti, Herrera \& Bustos, 2018). En ambos casos destaca un hábitat colectivo producto de una relativamente importante dimensión residencial, como consecuencia de un contexto de escasa población, de dispersión 
de los recursos explotables y de un territorio de particulares condiciones ambientales.

\section{Las viviendas de los campamentos}

El descubrimiento del petróleo el 29 de diciembre de 1945 en el sector de Cerro Manantiales, en el noroeste de la Isla Grande de Tierra del Fuego, determinó la instalación de manera permanente en dicho lugar de lo que hasta ese momento habían sido instalaciones móviles para la exploración de yacimientos productivos. En las cercanías del primer yacimiento productivo del país se instalaron las primeras unidades habitacionales del personal, se trató de pequeños módulos prefabricados de madera para obreros, los que fueron dispuestos, aparentemente sin un trazado previo, junto a las edificaciones destinadas al soporte de la explotación petrolífera (Fig. 4).

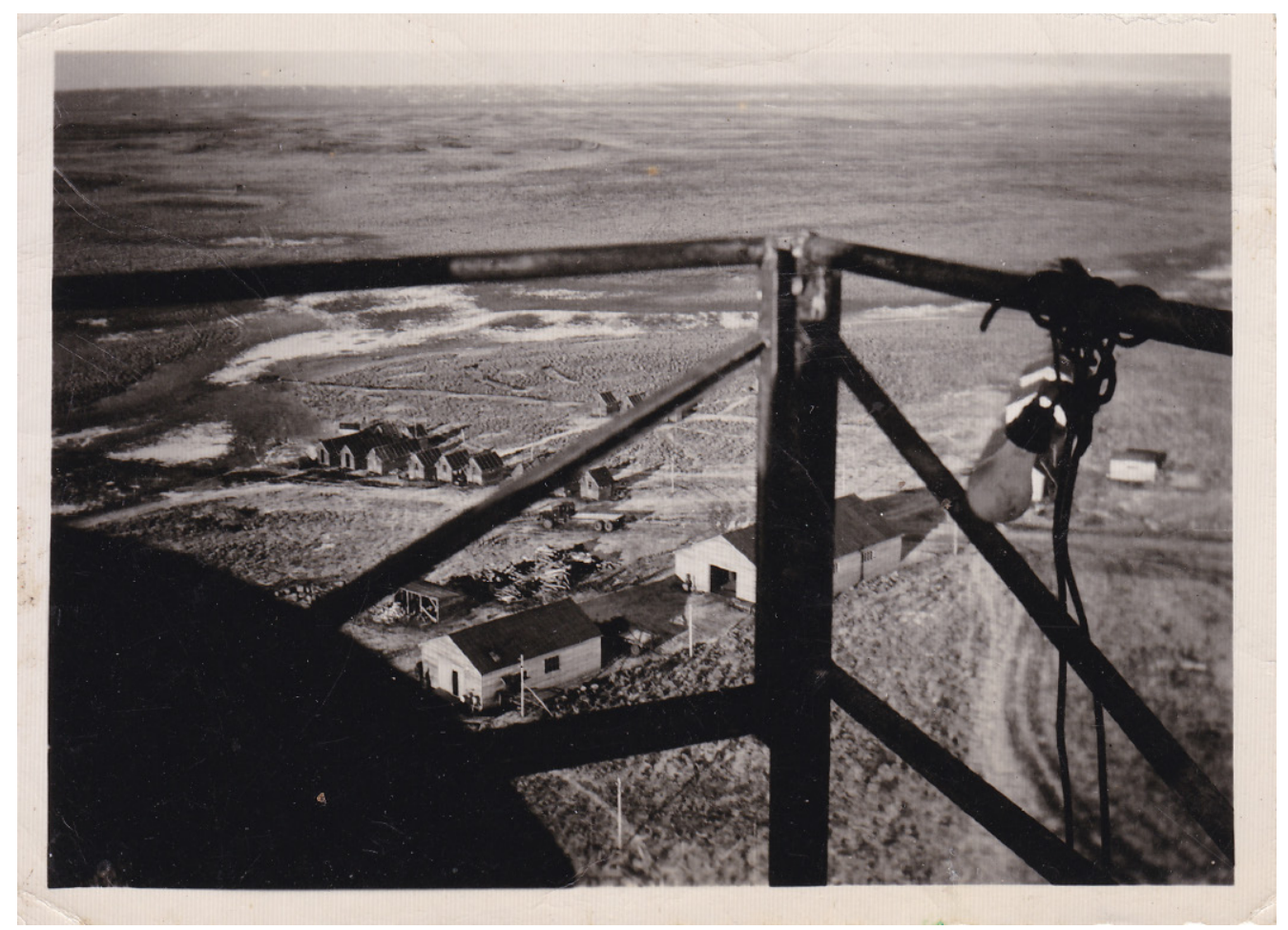

Fig. 4. A la izquierda de la imagen módulos habitacionales de instalaciones móviles. Fuente: Archivo Ricardo Sandoval.

Si bien el sector del Cerro Manantiales fue el primer lugar donde se fijaron instalaciones para el alojamiento a partir de 1945, las primeras viviendas definitivas para personal permanente con familias fueron proyectadas por la ENAP en el sector de Bahía Clarencia, a setenta kilómetros de las instalaciones de Manantiales. Asociadas al Terminal Marítimo de petróleo, construido a partir de 1950, se edificaron seis viviendas unifamiliares entre 1950 y 1953, con una capacidad de cuarenta y dos residentes. Viviendas hoy en día inexistentes (Fig. 5). 


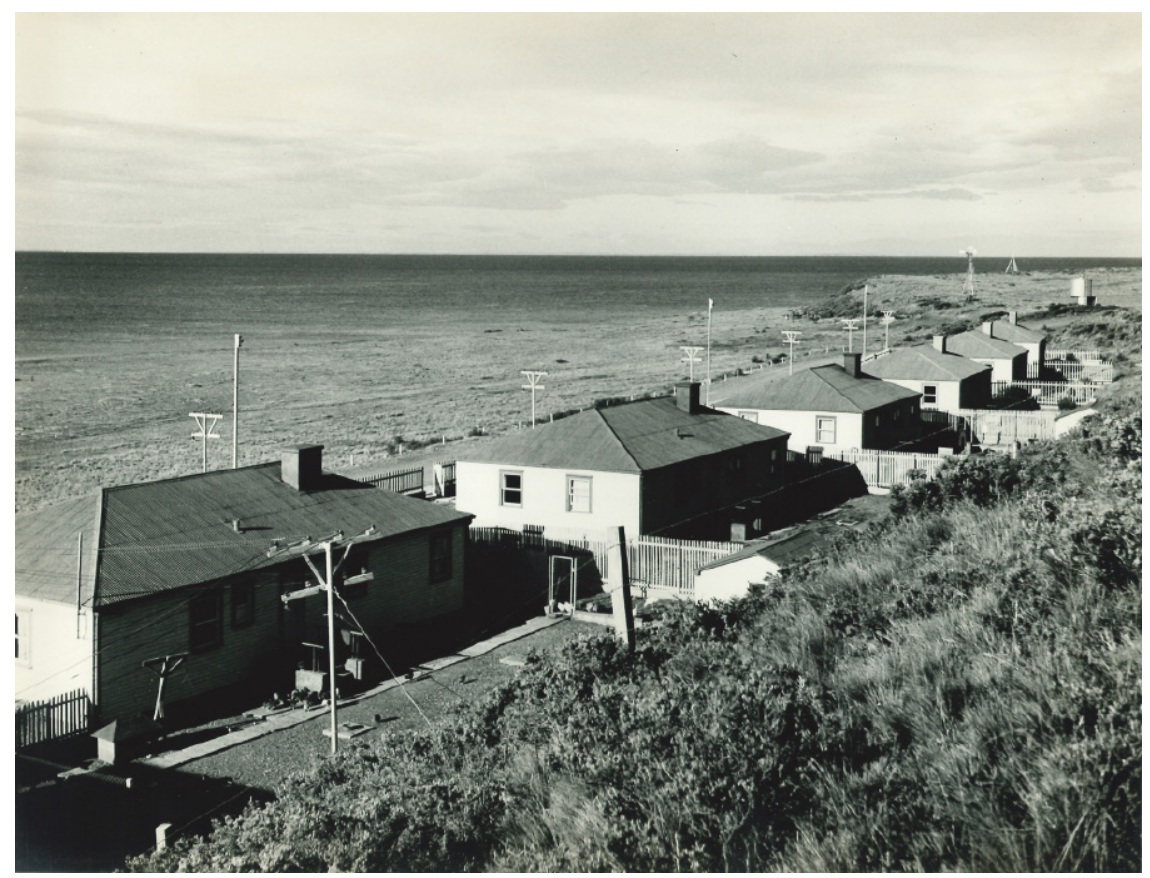

Fig. 5. Viviendas para empleados campamento Clarencia.

Fuente: Biblioteca del Congreso Nacional de Chile.

Éstas, dispuestas en una línea paralela a la costa, contemplaron dos plantas de idéntica superficie totalizando 251,6 m², un zócalo semienterrado de hormigón armado, con dos dormitorios y un baño aparentemente para personal de servicio, y una primera planta, que consideró tres dormitorios, un baño común, un estar, un comedor, una despensa y cocina, además de un acceso secundario hacia el piso zócalo (Fig. 6).

Mientras, en el año 1953, en el área de acceso a las instalaciones industriales se conformó el sector de obreros del Terminal Clarencia, también actualmente inexistente, donde se situaron, en cuatro pequeños edificios de madera, ocho viviendas, cada una de dos dormitorios, living, cocina y baño; además de una vivienda colectiva de cuatro dormitorios, y una edificación destinada a comedor común de obreros y empleados (Fig. 7). En base a estas instalaciones la empresa formó "el campamento del puerto petrolero en Tierra del Fuego" (ENAP, 1954, p. s/n). Finalmente, hacia 1962, junto a las viviendas de obreros la empresa complementó el ámbito residencial con ocho unidades habitacionales para obreros y sus familias, totalizando 22 unidades habitacionales para el campamento ${ }^{5}$.

Posteriormente, en 1954, distante aproximadamente seiscientos metros del conjunto primitivo en torno al primer yacimiento de Cerro Manantiales, en una urbanización compuesta de diecisiete viviendas aisladas (ENAP, 1955a, p. 12), una plaza y arborización, se configuró un sector residencial destinado a empleados de la empresa y sus familias. El proyecto, 

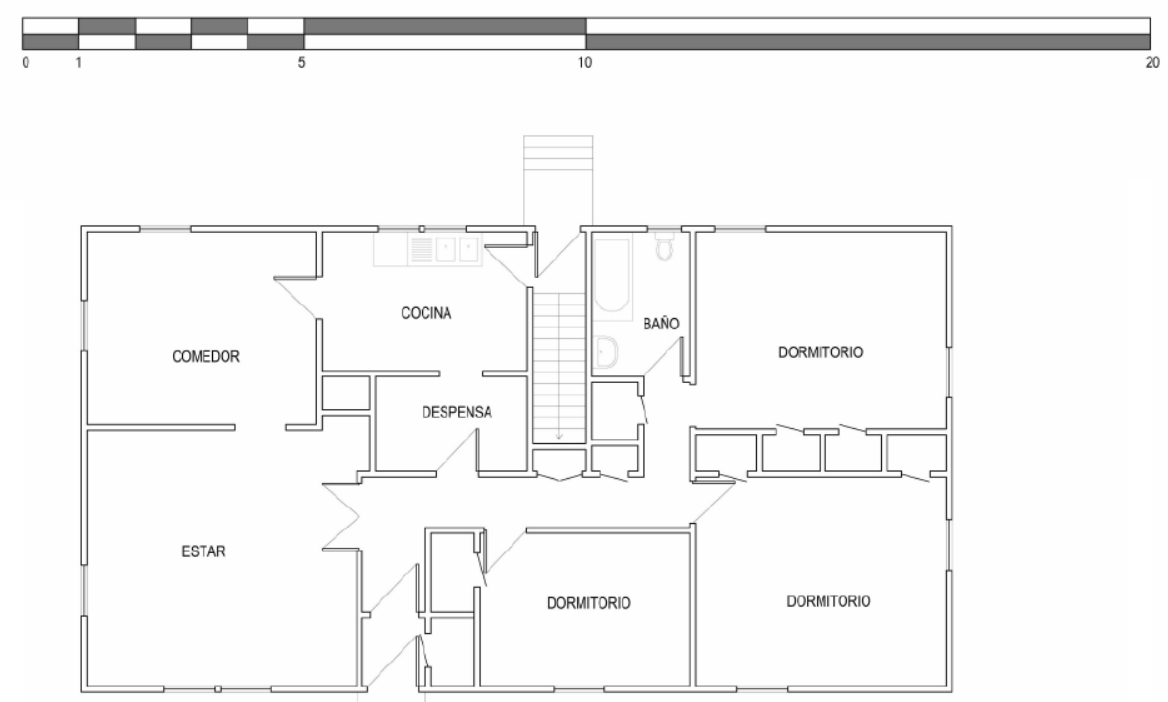

\section{PLANTA PRIMER NIVEL}

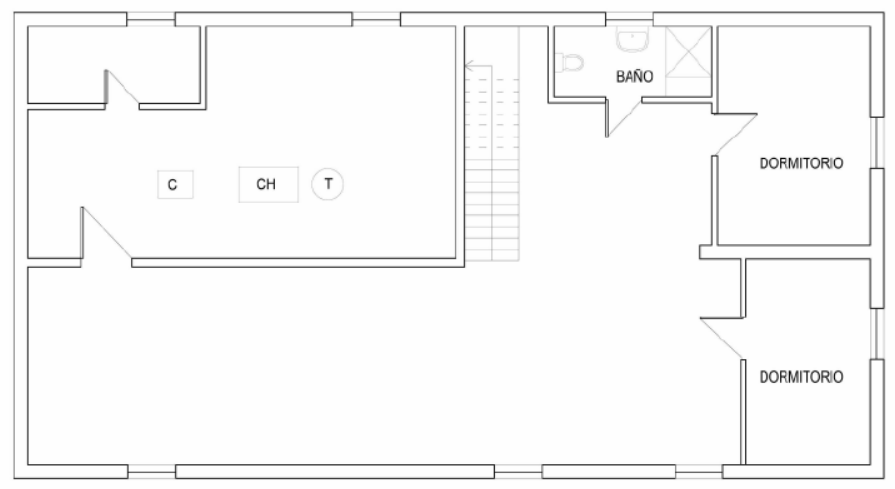

\section{PLANTA NIVEL SUBTERRÁNEO}

Fig. 6. Planta de vivienda para empleados, Puerto Clarencia. Fuente: ENAP (1985). Dibujo: Carolina Márquez C.

primer conjunto planificado para el alojamiento de empleados y familias, fue desarrollado por el arquitecto Jorge Claude Fonck ${ }^{6}$ y construido el año 1954. Este conjunto constituyó de parte de la empresa el inicio de una política para satisfacer la demanda por vivienda de sus trabajadores, tal como lo manifestó en su memoria anual de 1952:

6 Jorge Claude Fonck, arquitecto titulado de la P. Universidad Católica en 1949 (Strabucchi, 1994, p. 144), fue hijo del ingeniero Luciano Claude Sarasin, Jefe de Energía y Combustible de la CORFO y, posteriormente, Asesor Técnico de la ENAP (ENAP, 1952). 
B. Cvitanic \& D. Matus

PLANO UBICACIÓN

S/E

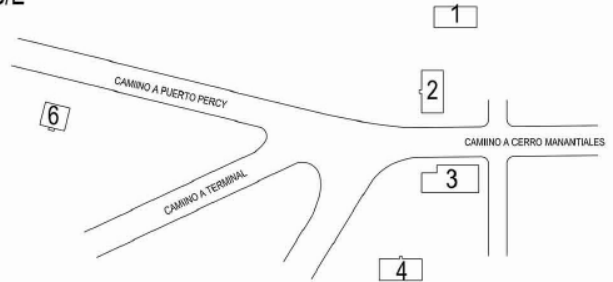

5
PLANTA VIVIENDA OBREROS (1)

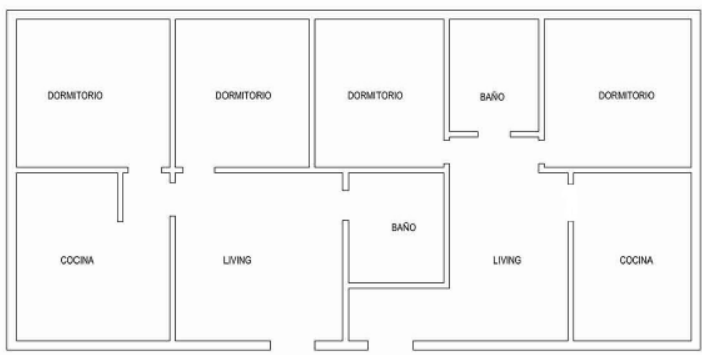

\section{PLANTA COMEDOR OBREROS (3)}

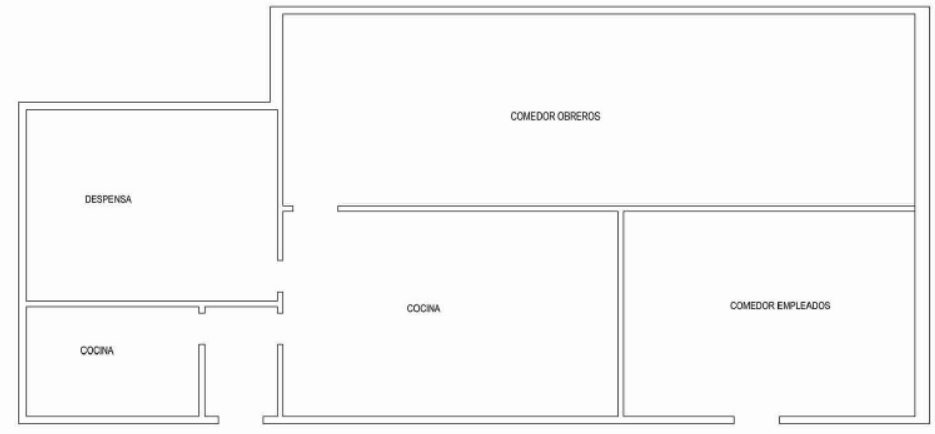

VIVIENDA OBREROS (4)

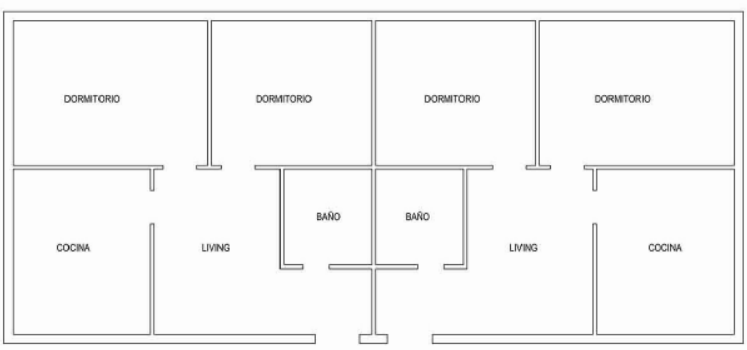

PLANTA VIVIENDA OBREROS (2)

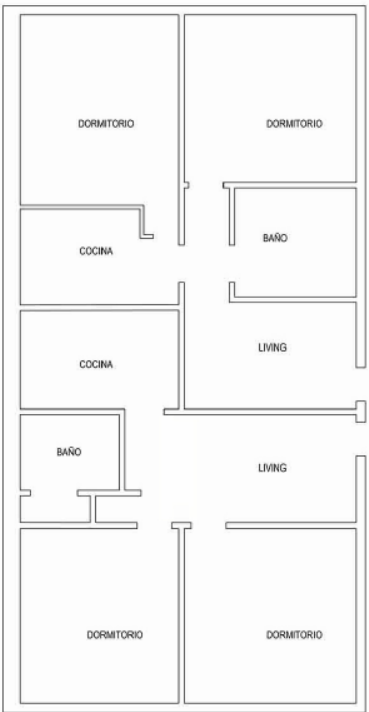

VIVIENDA OBREROS (5)

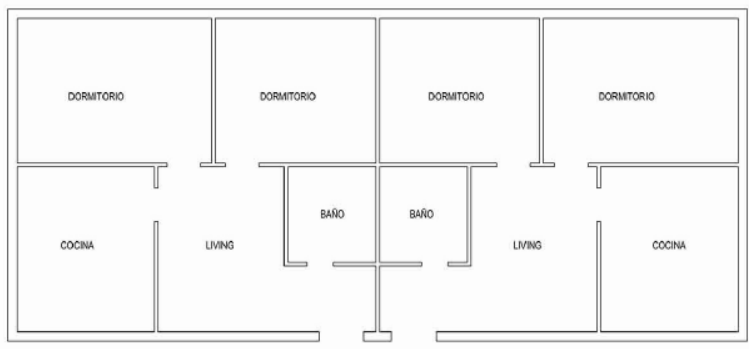

VIVIENDA OBREROS (6)

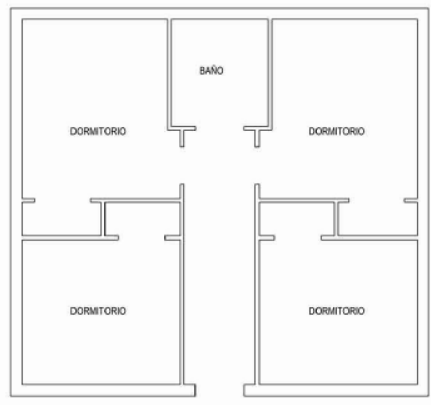

Fig. 7. Planta de viviendas para obreros, Puerto Clarencia. Fuente: ENAP (s.f.). Dibujo: Carolina Márquez C. 
Se resolvió, además, iniciar la construcción de una población para los empleados que prestan permanentemente sus servicios en Manantiales, con el objeto que puedan vivir permanentemente con sus respectivas familias en ese campamento.

Las obras, que se iniciarán a principios de 1953, contemplan la construcción de unas 15 a 20 casas... y representan una sentida necesidad de los empleados.

Paralelamente con esta resolución se acordó abordar el problema de habitaciones para los obreros, y estudiar un plan integral que signifique dar solución definitiva en este aspecto para todos los empleados y obreros que prestan sus servicios, con carácter más o menos permanente, en Tierra del Fuego. Es este un vivo deseo de la empresa y conjuntamente con ello dotar a esta población o grupo de poblaciones de un mejor Servicio Médico del que actualmente se dispone, con el fin de atender a las familias, y con las Escuelas necesarias para la instrucción de los niños de empleados y obreros" (ENAP, 1953, p. 1).

Ambos sectores del asentamiento de Manantiales, el inicial con las viviendas prefabricadas de obreros, además de las instalaciones productivas, y el sector de empleados con familias, fueron posteriormente complementados con equipamientos comunes como gimnasio, escuela y policlínico, los que fueron emplazados en un punto central del campamento ${ }^{7}$.

En Percy, en la bahía Gente Grande, distante a diez kilómetros del Terminal Clarencia, junto a las instalaciones portuarias para el embarque de gas y para el desembarque de materiales y provisiones de las faenas de la ENAP en la isla de Tierra del Fuego, la empresa planificó en 1957 la urbanización y las edificaciones de un campamento, esta vez para obreros, empleados y choferes. El proyecto fue desarrollado ex-nihilo por la ENAP, siendo el arquitecto Víctor Arancibia M., funcionario de la Sección Arquitectura de la empresa (ENAP, 1958, p. 17), el encargado de desarrollar los diseños. Se trató de un conjunto de 21 viviendas de un nivel, quince de ellas pareadas, destinadas a obreros y choferes, y tres aisladas, destinadas a empleados, además de un edificio que alojó la escuela, el cine, el casino, una sala de juegos y un pabellón de dormitorios para personal de aduanas y funcionarios en roles, totalizando una capacidad de ciento cuarenta y seis residentes (ENAP, 1987).

Los proyectos de viviendas para empleados y para obreros y choferes fueron desarrollados entre 1956 y 1957. Se trató, a diferencia de lo ocurrido en Manantiales y en Clarencia, de respuestas y diseños similares para ambas categorías de trabajadores, las primeras se desarrollaron en una distribución en planta en forma de "T”, con dos sectores diferenciados, un área diurna y pública, y un área nocturna y privada; en su programa arquitectónico los modelos de viviendas presentaron tres dormitorios, un baño común, una galería, un hall, un living, comedor, cocina, lavadero, garage, despensa y un dormitorio de servicio, con capacidad para dos camas y un baño (Fig. 8). A la vez, las viviendas de obreros y choferes se desarrollaron en una distribución en planta en forma de "L", con un acceso central. Hacia un lado del acceso quedaron ubicados los recintos diurnos, living-comedor, cocina, despensa y lavadero, y, en su costado opuesto, los recintos privados,

Según Garcés et al. (2007, p. 36) el campamento de Manantiales habría llegado a contemplar doscientos veintisiete residentes.

8 Según Garcés et al. (2007, p. 36) el campamento de Percy habría llegado a contemplar setenta residentes. 

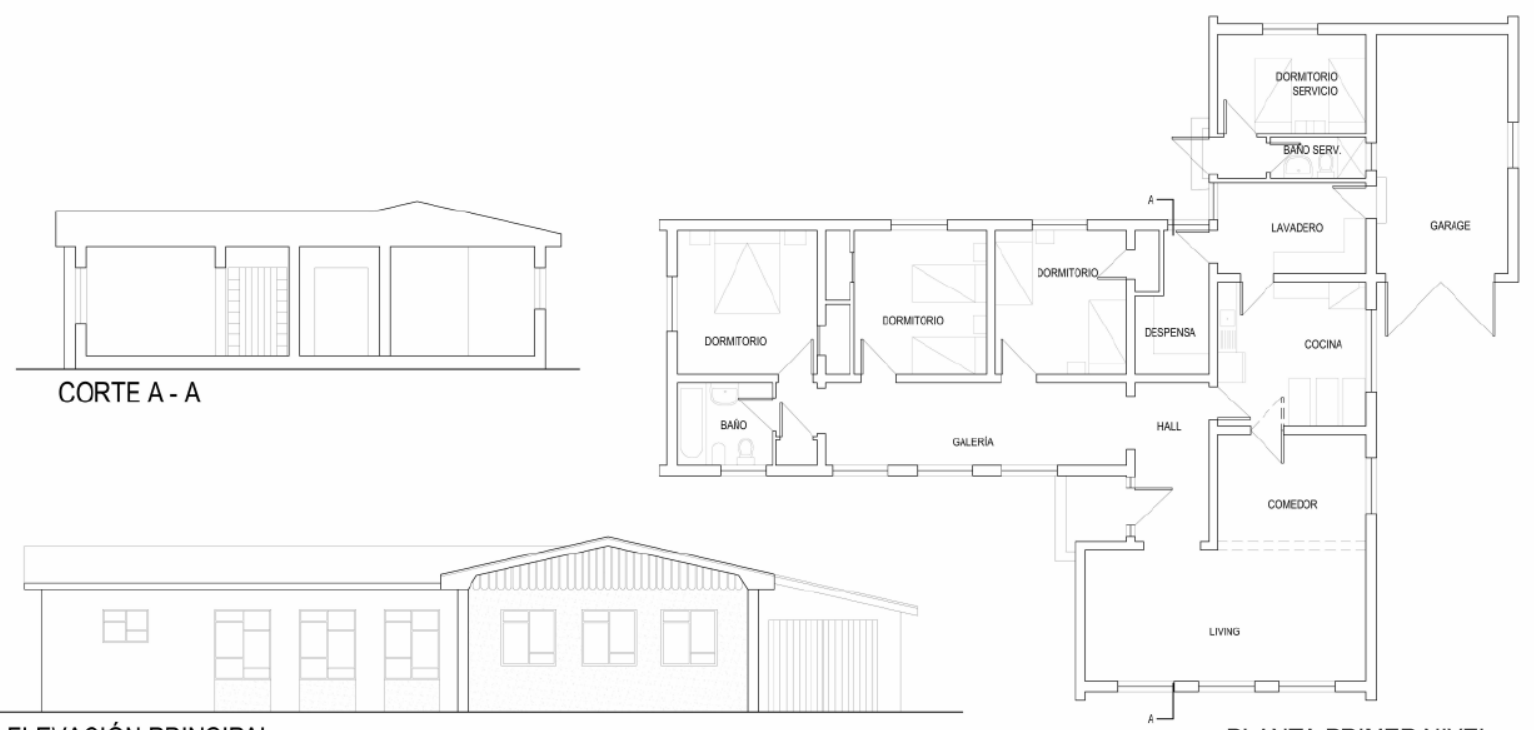

ELEVACIÓN PRINCIPAL

PLANTA PRIMER NIVEL

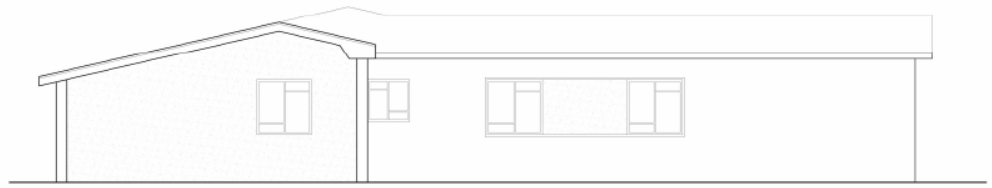

ELEVACIÓN POSTERIOR

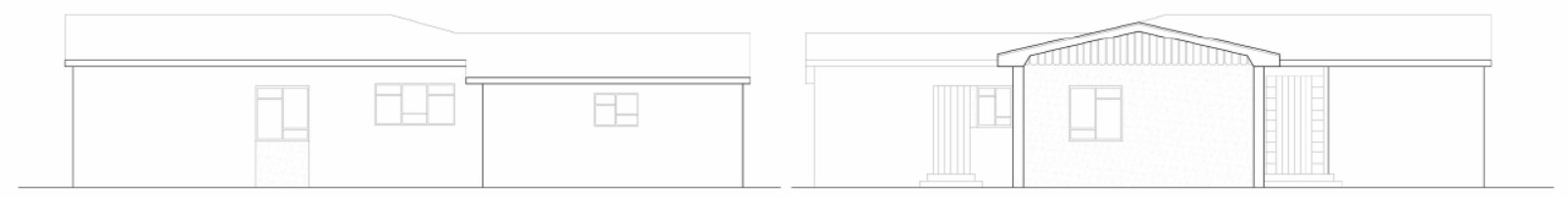

ELEVACIÓN LATERAL

ELEVACIÓN LATERAL

Fig. 8. Planta y elevaciones viviendas para empleados, campamento de Percy. Fuente: ENAP (1956a). Dibujo: Carolina Márquez C.

compuestos de tres dormitorios y un baño común (Figs. 9 y 10).

A partir de 1955 se desarrollaron los proyectos de arquitectura de las viviendas para el campamento de Cerro Sombrero, posteriormente, desde 1956, se elaboraron los proyectos de equipamientos y otras instalaciones para el mismo (cine, escuela, gimnasio, piscina y jardín cubierto, pulpería, policlínico, casino de trabajadores, observatorio y capilla).

$\mathrm{Al}$ igual que el campamento de Percy, Cerro Sombrero fue proyectado y construido 
ex-nihilo, esta vez no sobre un llano sino que sobre una pequeña colina, junto al río Side, como centro administrativo y logístico de las labores productivas en la Isla Grande de Tierra del Fuego ${ }^{9}$. El diseño del campamento presentó una mayor diversidad en las respuestas residenciales, tanto en la clasificación socioespacial de los residentes, al igual que Percy para empleados, obreros y choferes, como también por presentar alternativas en los diseños de viviendas. En base al proyecto de conjunto (ENAP, 1966a), el campamento de Cerro Sombrero consideró inicialmente una capacidad aproximada de setecientos residentes ${ }^{10}$.

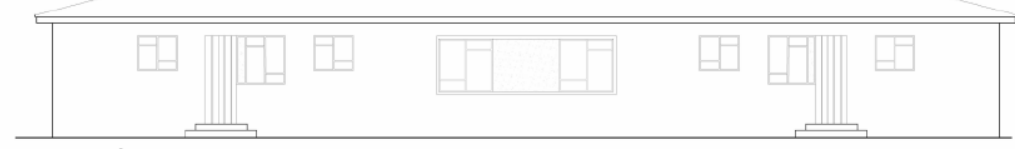

ELEVACIÓN POSTERIOR

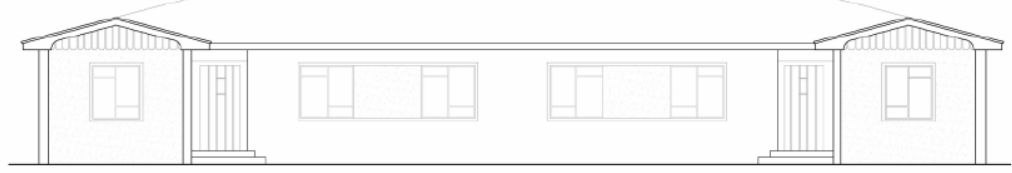

ELEVACIÓN PRINCIPAL

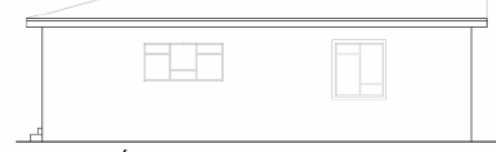

ELEVACIÓN LATERAL

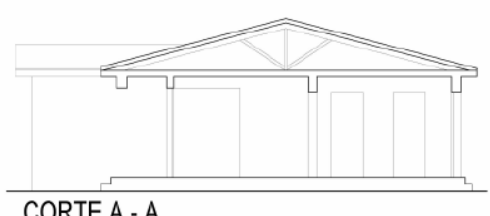

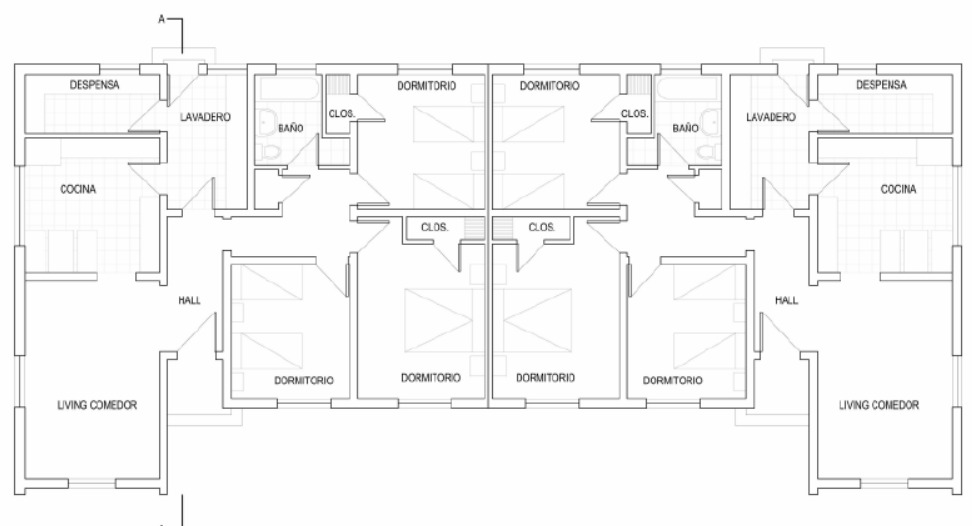

PLANTA PRIMER NIVEL

Fig. 9. Planta y elevaciones viviendas para obreros y choferes, campamento de Percy. Fuente: ENAP (1956b). Dibujo: Carolina Márquez C.

9 El área de explotación administrado por el campamento de Cerro Sombrero correspondió aproximadamente a $4.000 \mathrm{~km}^{2}$ en territorio insular de la Isla Grande de Tierra del Fuego.

10 Según Garcés et al. (2013, p. 133), en 1960 el campamento de Cerro Sombrero tenía setecientos tres residentes, en ciento catorce viviendas, mientras que en 1970 habría llegado a novecientos, en ciento cuarenta viviendas. 


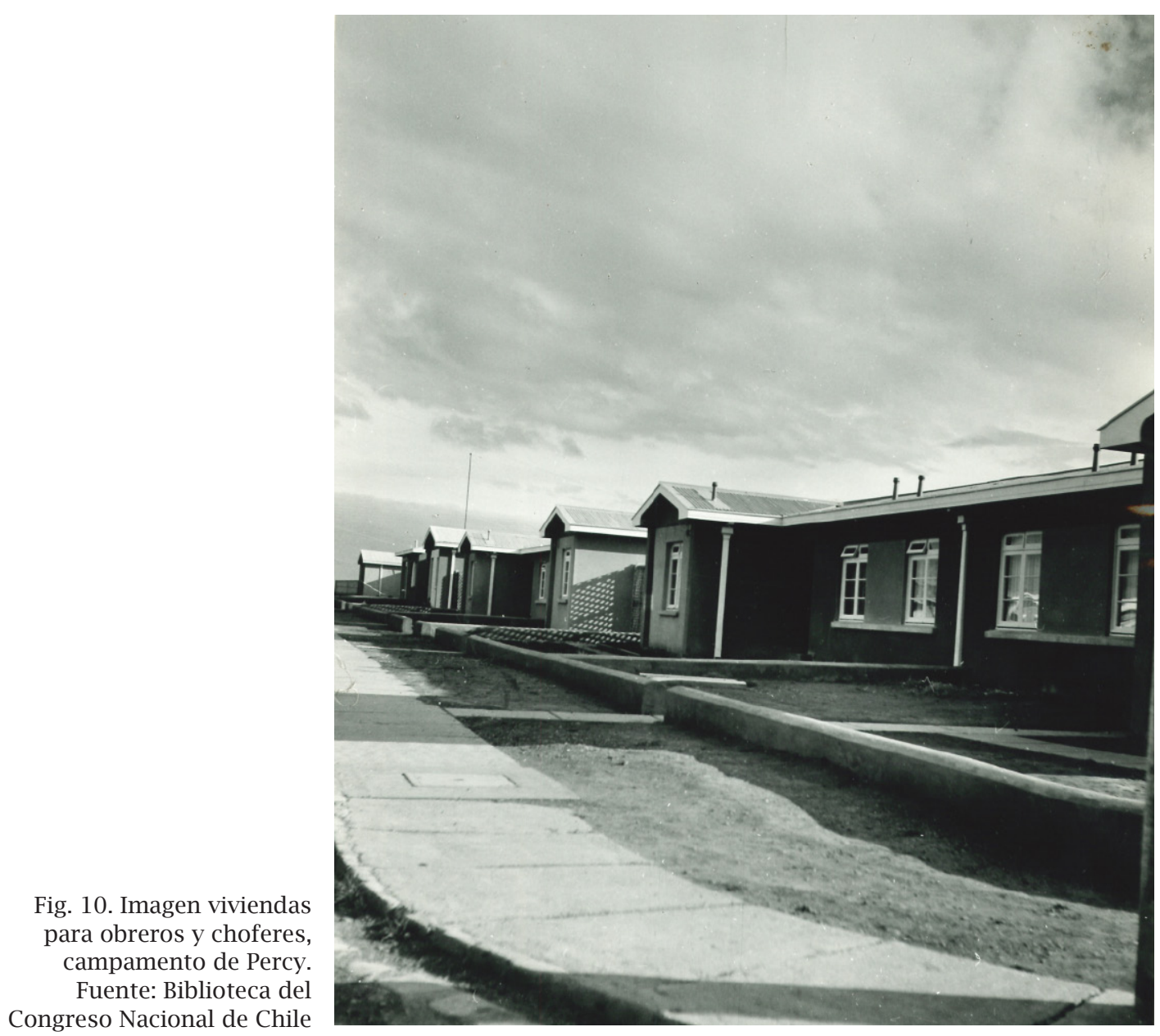

El campamento presentó diferentes propuestas para trabajadores con familia, tanto para empleados, como también para obreros y para choferes, además de vivienda colectiva para personal soltero en roles. Con excepción de los pabellones de obreros solteros, los que fueron construidos en base a módulos prefabricados sobre patines ${ }^{11}$, la totalidad de las viviendas fueron proyectadas y construidas en hormigón armado, albañilería y madera, para su estructura, lo que, al igual que las viviendas de empleados de Clarencia y la totalidad del campamento de Percy, las convirtió en obras permanentes.

Para las viviendas de empleados, proyectadas durante 1955 por el arquitecto Víctor Arancibia M., la empresa desarrolló dos alternativas similares, denominadas A (Fig. 11) y B (Fig. 12), ambas fueron viviendas unifamiliares aisladas de dos niveles, de $192 \mathrm{~m}^{2}$ (ENAP, 1955b) y de $246 \mathrm{~m}^{2}$ (ENAP, 1955c) respectivamente, diferenciándose en la cantidad de dormitorios: dos para la primera y tres para la segunda alternativa. Ambos modelos se organizaron en un

11 Nombre coloquial de vigas, en este caso de madera, sobre las que se estructura cada módulo. Éstas sobresalen en ambos lados de los módulos (en sus caras angostas) para ser alzados y transportados. Suelen ser el elemento sobre el que disponen los módulos sobre el terreno, cumpliendo el rol de fundaciones. 


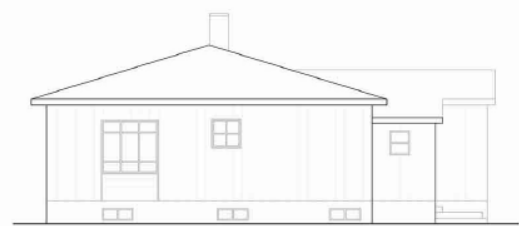

ELEVACIÓN LATERAL

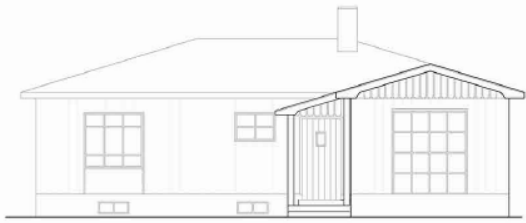

ELEVACIÓN PRINCIPAL
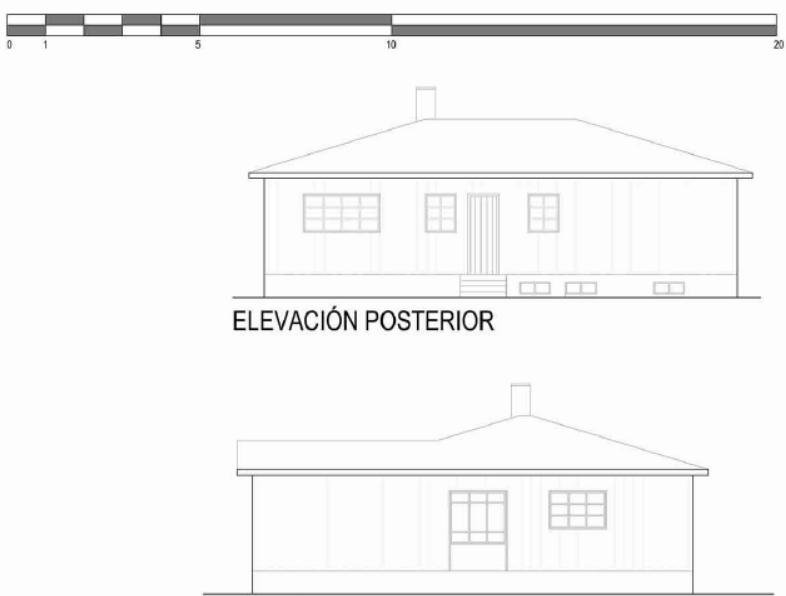

ELEVACIÓN LATERAL

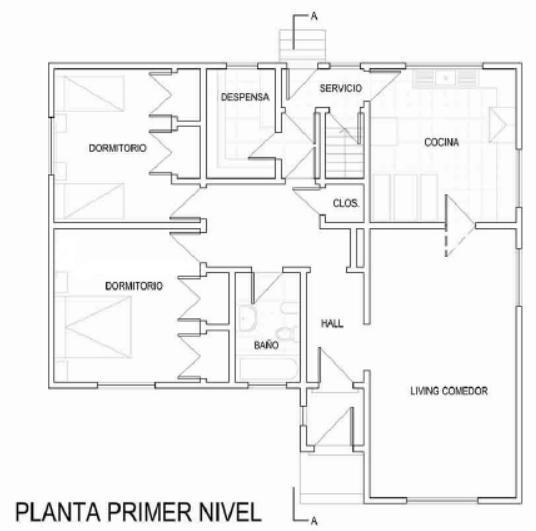

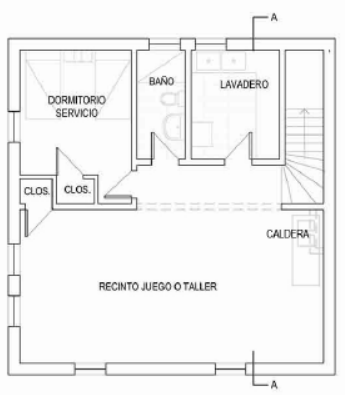

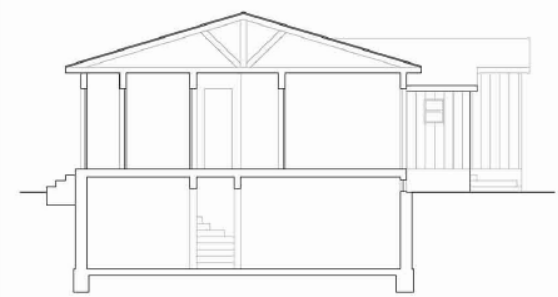

CORTE A - A

PLANTA NIVEL SUBTERRÁNEO

Fig. 11. Planta de vivienda empleados modelo A, campamento de Cerro Sombrero. Fuente: ENAP (1955d). Dibujo: Carolina Márquez C.

esquema en forma de "L", con un sector público y otro privado a partir del acceso situado en el centro. En el sector público se dispusieron el living, el comedor, la cocina, despensa y escalera que permite descender al zócalo; mientras que en el sector privado se ubicó un baño y los dormitorios. Por su parte, en el zócalo, con una planta cuadrada bajo el área privada de la vivienda, se ubicó un dormitorio de servicio, con baño, además de caldera, lavadero y un "recinto [de] juegos o taller" (ENAP, 1955c).

Las viviendas de obreros, desarrolladas como unidades habitacionales pareadas de un nivel, con una superficie de $97,8 \mathrm{~m}^{2}$, fueron ordenadas en base a un esquema similar al de las viviendas de empleados, consideraron en su programa arquitectónico living-comedor, cocina, lavandería y despensa en su sector diurno, y, en el ala opuesta, tres dormitorios y un baño común. 

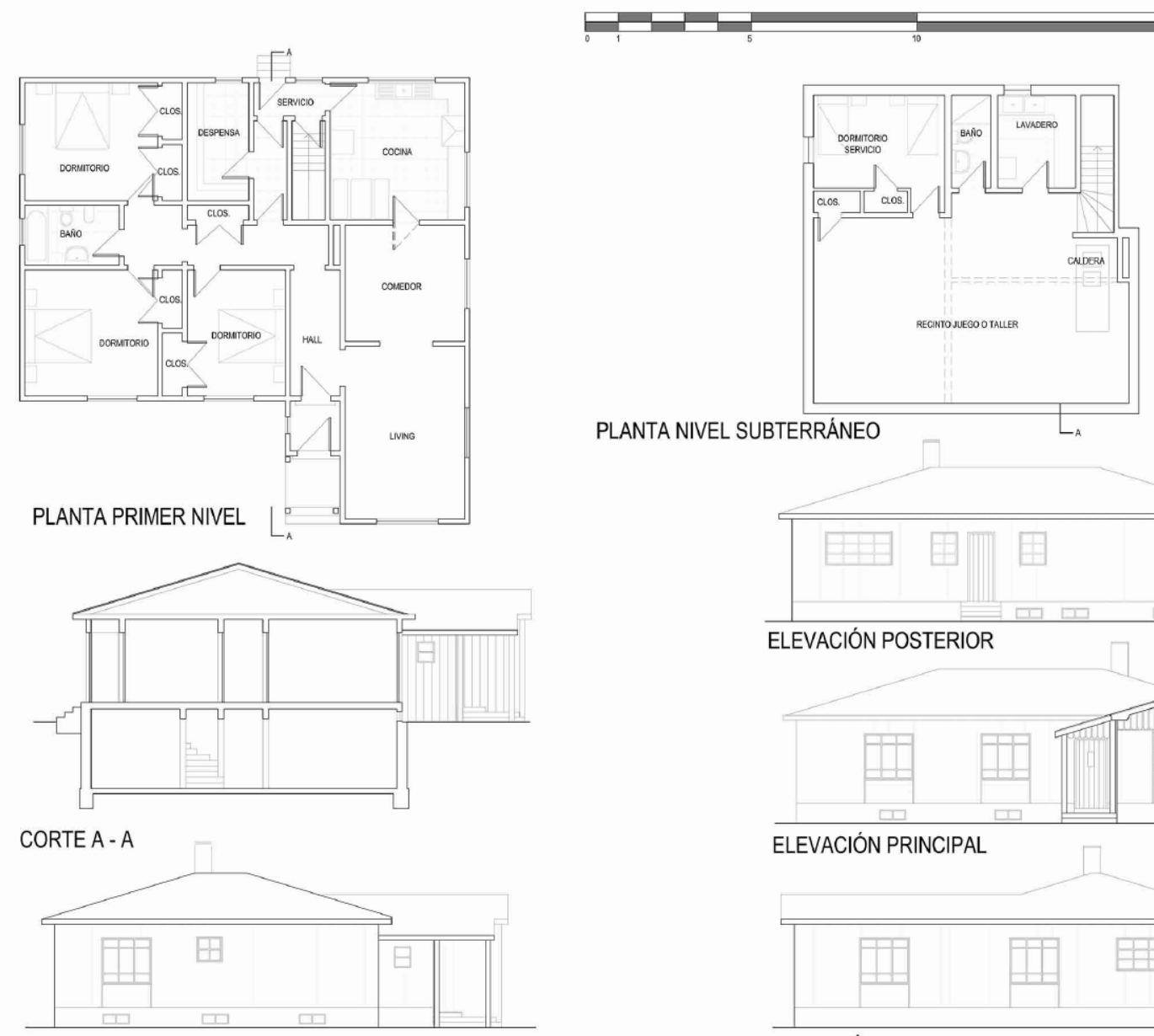

ELEVACIÓN LATERAL
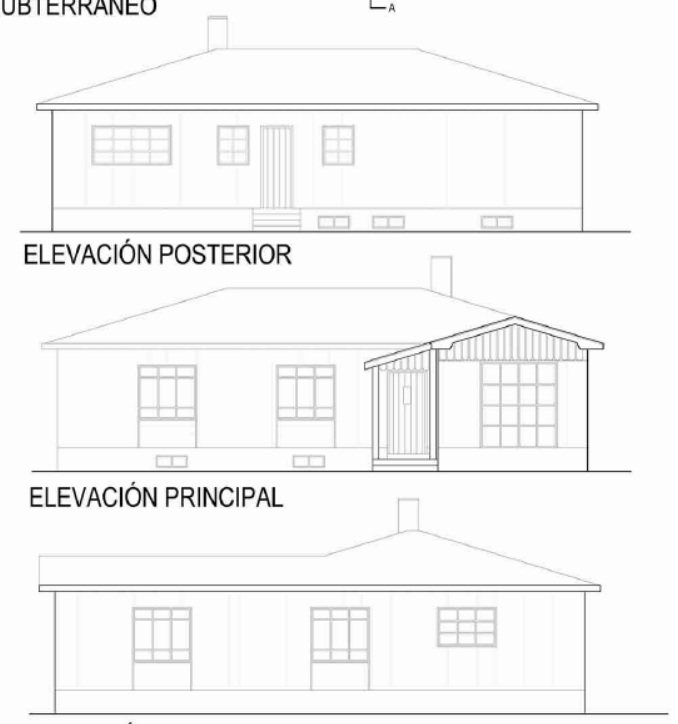

ELEVACIÓN LATERAL

Fig. 12. Planta de vivienda empleados modelo B, campamento de Cerro Sombrero Fuente: ENAP (1955d). Dibujo: Carolina Márquez C.

Por su parte, las viviendas de choferes también fueron desarrolladas como unidades

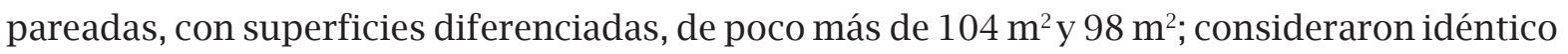
programa consistente en un dormitorio principal, dos dormitorios menores, living-comedor, cocina y, al igual que las viviendas de empleados, un dormitorio de servicio, además de un baño común en cada nivel (Fig. 13).

Finalmente, la dimensión residencial del campamento se completó con un pabellón colectivo para empleados y choferes, construido en hormigón armado, y siete pabellones para obreros, conformados en base a módulos prefabricados de madera. El primero contempló para choferes cinco dormitorios y un baño, mientras que para empleados se habilitaron doce dormitorios, un estar y dos baños comunes (ENAP, 1957). Los pabellones de obreros, que consideraron cantidades variables de módulos, consistieron de dormitorios, baños y duchas comunes, y un living-comedor (Fig. 14). 


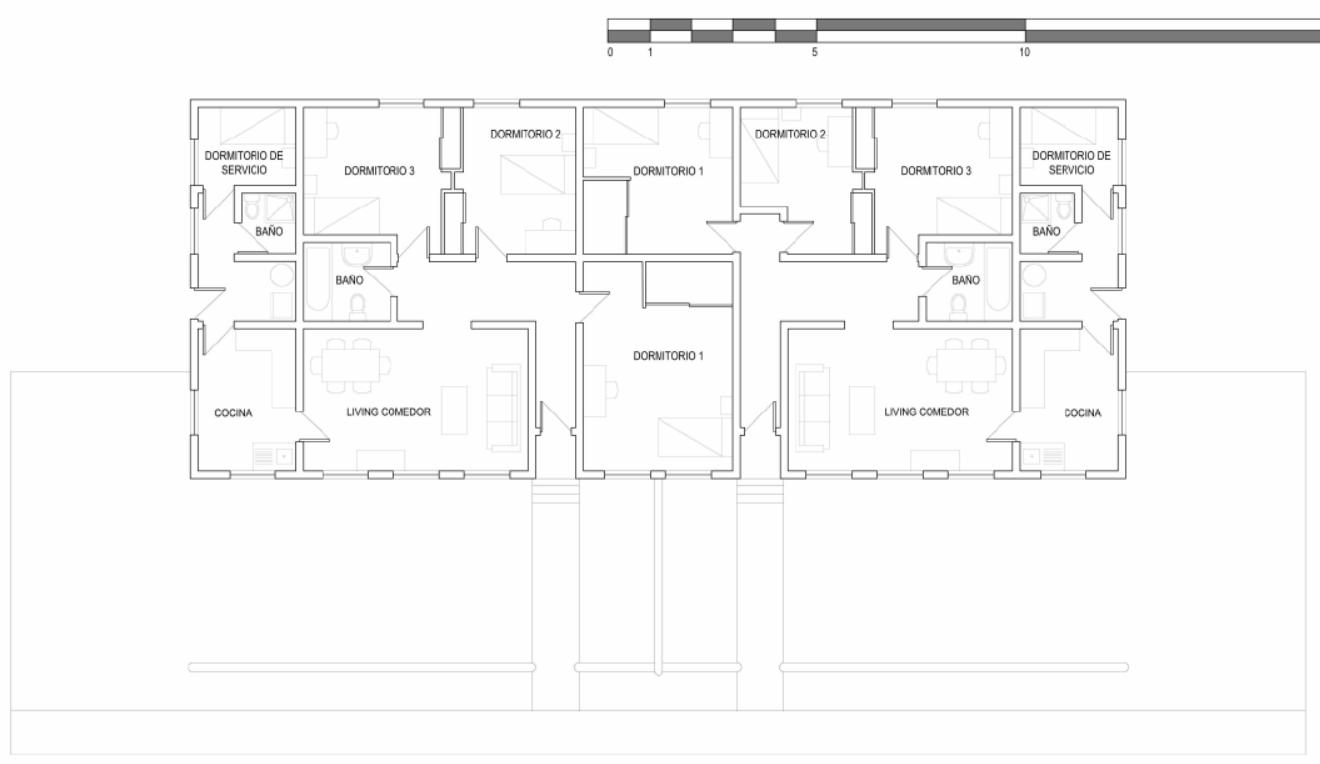

PLANTA GENERAL

ELEVACIÓN PRINCIPAL
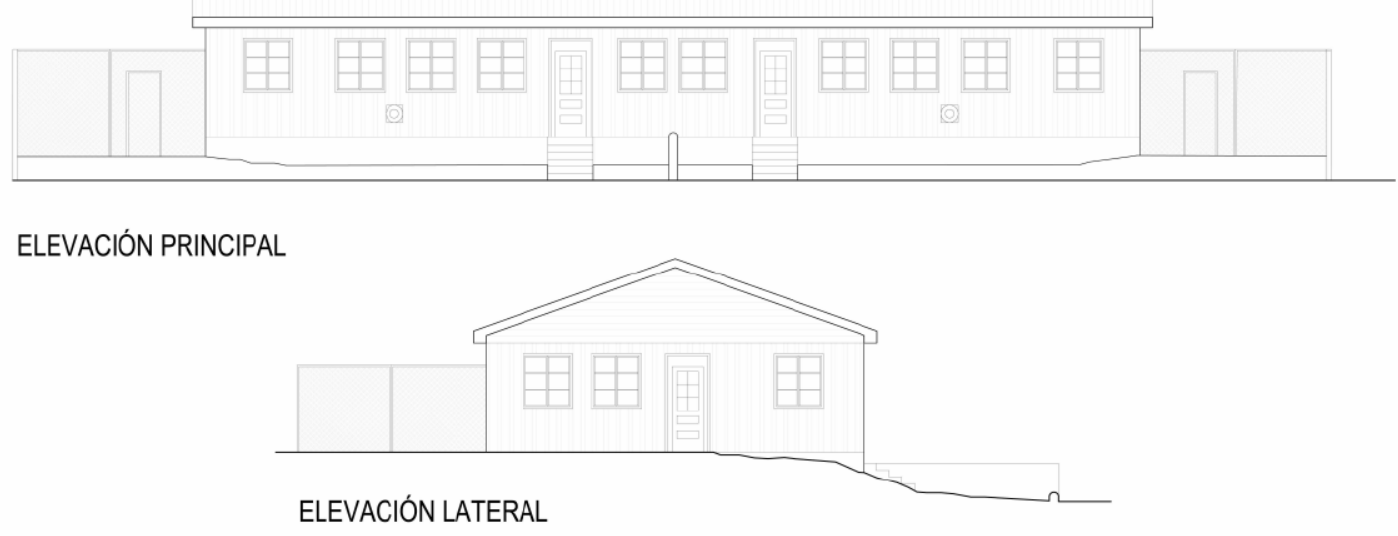

Fig. 13. Planta de viviendas para choferes, campamento de Cerro Sombrero. Fuente: Domínguez (2011). Dibujo: Carolina Márquez C.

Durante el año 1960 se finalizó el diseño del campamento de Cullen, junto a la planta de tratamiento de gasolina. Como parte de un conjunto a ser emplazado a sesenta kilómetros del campamento de Cerro Sombrero, se configuraron dos sectores de viviendas: para empleados, separado del núcleo central del campamento; y para obreros, asociado a los equipamientos comunes, en este último sector además se ubicaron dos pabellones de dormitorios, uno para empleados y otro para obreros, como parte del edificio del Casino. Esta vez los diseños se inscribieron en un proceso de estandarización de las soluciones habitacionales por parte de la empresa: Tipos A y B, para obreros; y Tipos 100, 120 y 140, para empleados. En base al proyecto de conjunto (ENAP, 1985) y 

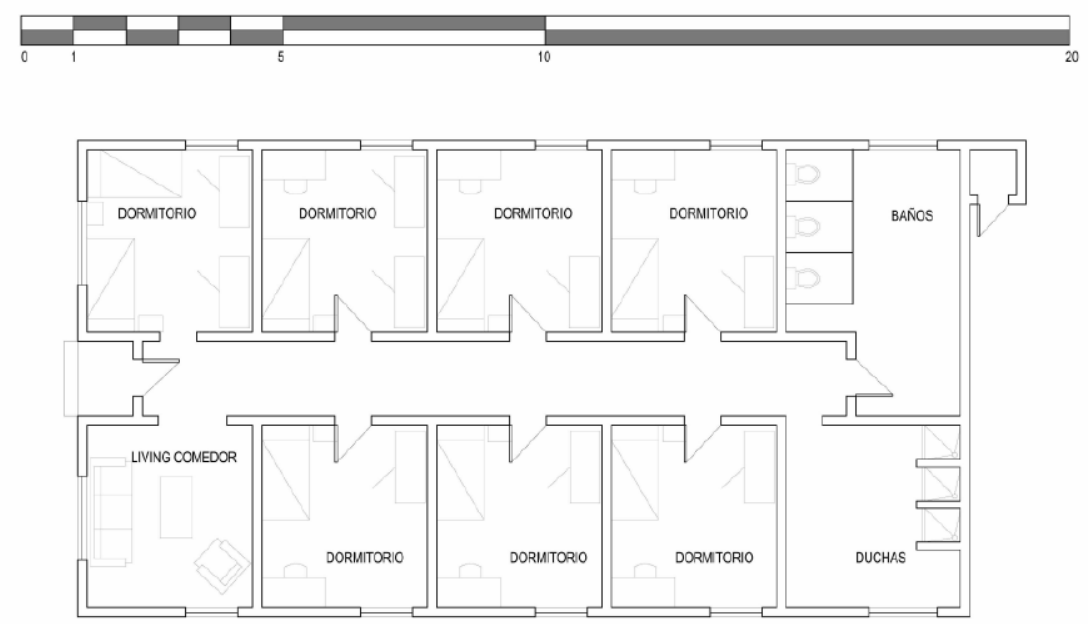

\section{PLANTA GENERAL}

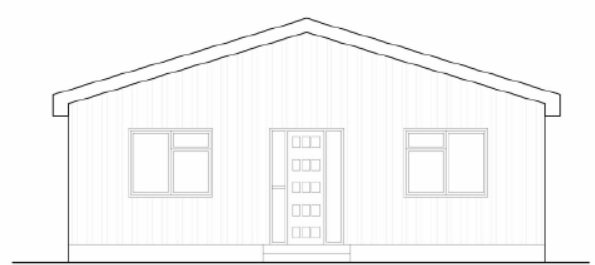

ELEVACIÓN PRINCIPAL

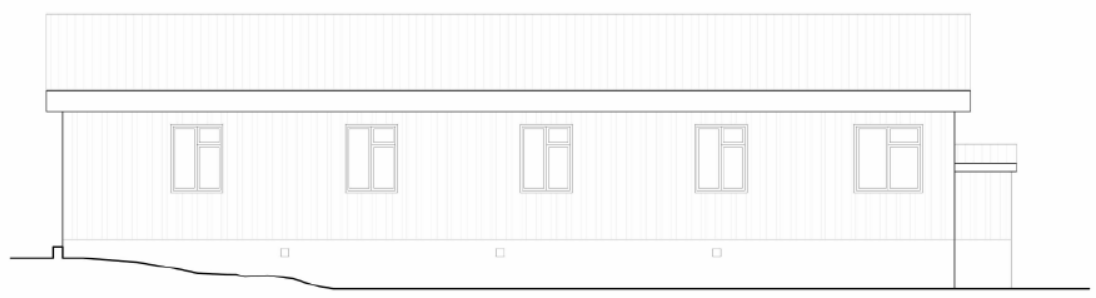

\section{ELEVACIÓN LATERAL}

Fig. 14. Planta de pabellón de obreros, campamento de Cerro Sombrero. Fuente: Domínguez (2011). Dibujo: Carolina Márquez C.

a los modelos de viviendas construidos el campamento Cullen totalizó una capacidad aproximada de quinientos cincuenta residentes ${ }^{12}$.

Los primeros, Tipos A y B fueron dispuestos en bandas o pareados, con superficies de $66,78 \mathrm{~m}^{2}$ y 75,14 m², según su ubicación en las manzanas. En términos de programa arquitectónico consideraron, en un cuerpo rectangular, un recinto de estar-cocina, tres

12 Según Garcés et al. (2007, p. 36) el campamento de Cullen habría llegado a contemplar trescientos veinticinco residentes. 
TIPOA
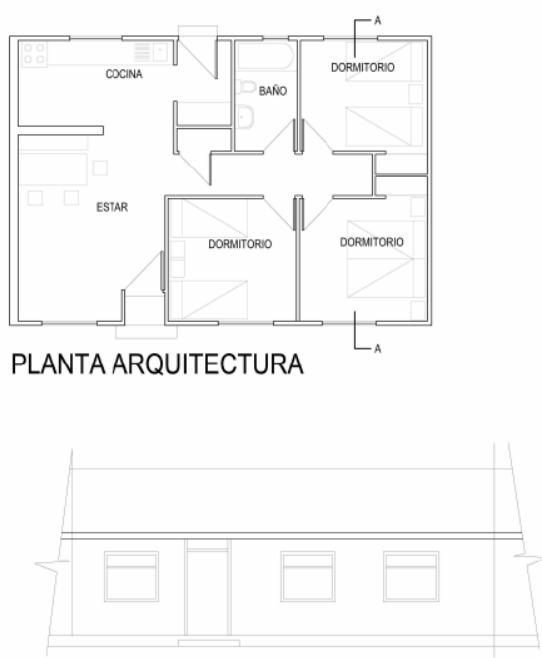

ELEVACIÓN PRINCIPAL

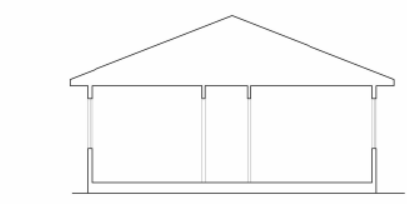

CORTE A-A

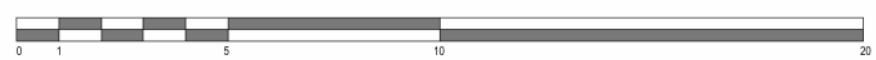

TIPOB
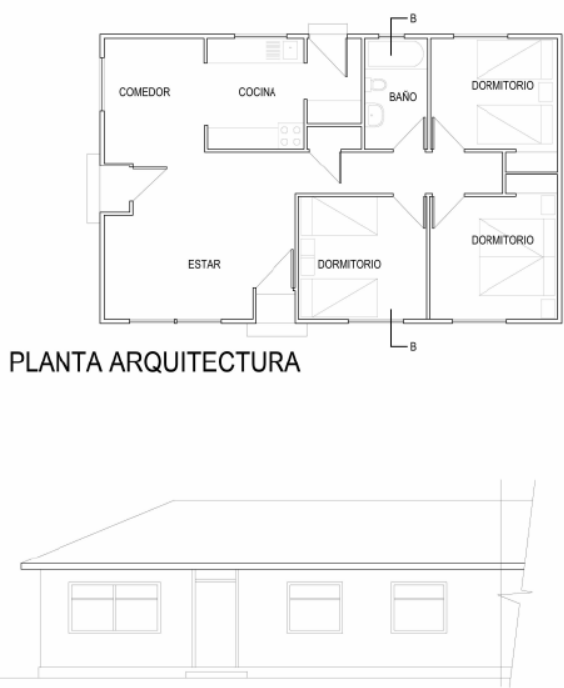

ELEVACIÓN PRINCIPAL

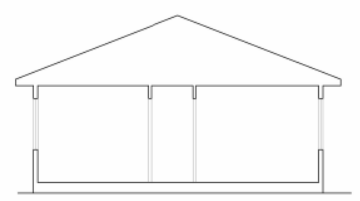

CORTE B-B

Fig. 15. Planta de vivienda para obreros Tipo A y Tipo B, campamento de Cullen. Fuente: ENAP (1982b). Dibujo: Carolina Márquez C.

dormitorios dobles y un baño común (Fig. 15). Mientras, las viviendas para empleados, catalogadas según sus superficies, fueron organizadas en base a un esquema en forma de "L" con su ala corta hacia el interior del predio, dispuesta así en sentido contrario a los modelos de viviendas de empleados de los campamentos de Percy y Cerro Sombrero. Consideraron similar programa que incluyó tres dormitorios, baño común, estar, comedor, cocina, despensa y lavadero, además de un dormitorio de servicio con baño (Fig. 16).

Por su parte, a ciento veinte kilómetros de la ciudad de Punta Arenas, en el sector continental de la explotación petrolera, se realizaron en 1961 los diseños del campamento de Gregorio, junto al terminal de embarque marítimo del mismo nombre, los que fueron construidos en 1962. Se trató de un pequeño conjunto de doce viviendas unifamiliares para empleados y dos destinadas a obreros, con una capacidad para el conjunto estimada en noventa y seis residentes (ENAP, 1966b). Las primeras, correspondieron a los diseños estándar 100 y 120 realizados por el arquitecto Víctor Arancibia M. (ENAP, 1961a), los 
S/E

TIPO 120

TIPO 100

PLANTA ARQUITECTURA

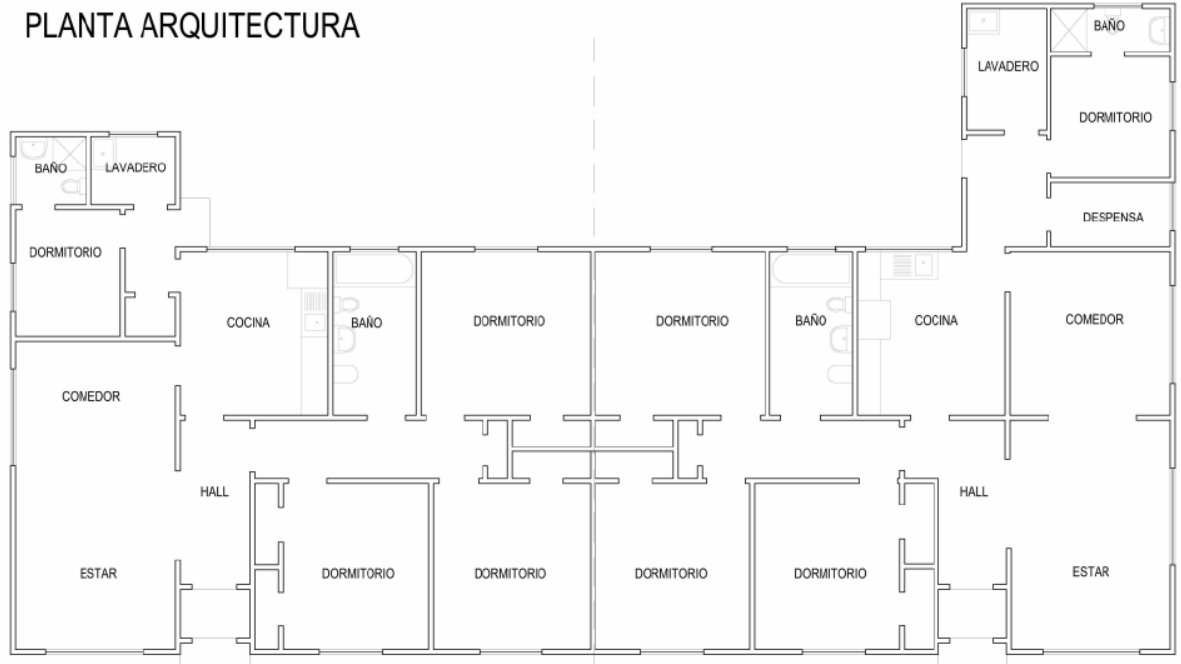

Fig. 16. Planta de viviendas para empleados "Tipo 100" y "Tipo 120". Fuente: ENAP (1962). Dibujo: Carolina Márquez C.

que habían sido previamente utilizados en Cullen, con la misma superficie y programa, incluyendo el dormitorio de servicio. Por su parte, las viviendas de obreros, diseño de los arquitectos Víctor Arancibia M. y Flor Vera L. (ENAP, 1961b), correspondieron a los modelos 84 y $84 \mathrm{~A}$, también fueron dispuestas en pareo, y contemplaron en su programa arquitectónico un recinto de estar-comedor, un dormitorio principal, dos dormitorios dobles, un baño común y cocina (Fig. 17). Se trató en estos modelos de una variación en superficie del modelo Tipo B implementado previamente en las viviendas para obreros en el campamento de Cullen.

La explotación de yacimientos en el sector continental de la boca oriental del estrecho de Magallanes determinó la configuración de un campamento a doscientos veintisiete kilómetros 


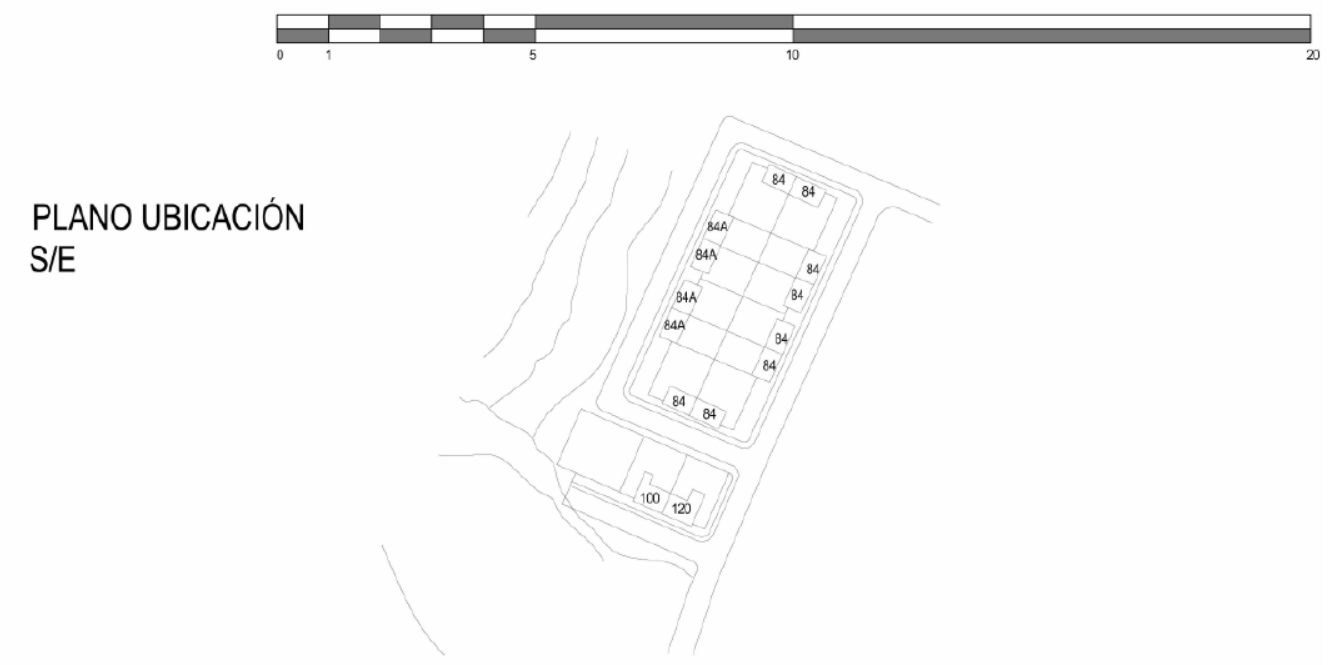

TIPO 84 A

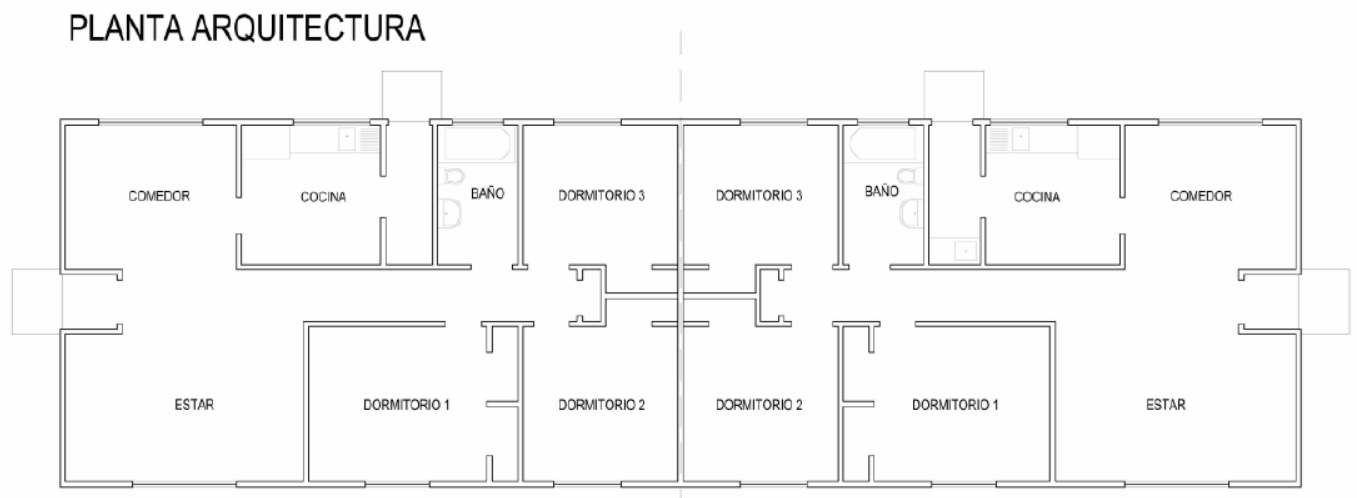

Fig. 17. Planta de viviendas para obreros Tipo 84A, campamento de Gregorio. Fuente: ENAP (1961b). Dibujo: Carolina Márquez C.

de distancia de la ciudad de Punta Arenas que, a diferencia del resto de instalaciones residenciales permanentes, fue mutando en relación con los cambios en las actividades industriales. A la constitución inicial del campamento de Posesión, como centro logístico de las labores extractivas del territorio continental oriental ${ }^{13}$, hacia fines de la década de 1950, le siguió la construcción de una planta de tratamiento en 1971, y posteriormente, a partir de 1980, el soporte logístico de la explotación petrolera en el lecho marino del estrecho. De este proceso constan dos momentos: uno inicial, entre fines de la década de 1950 y principios de la década siguiente, con la construcción de un indeterminado número de viviendas de obreros y los equipamientos comunes, además de un sector de treinta y siete viviendas de empleados, más una escuela y áreas verdes; y, en el año 1972, la construcción de un conjunto de veintiséis viviendas situadas junto a los equipamientos comunes. Las viviendas iniciales, tanto de obreros

13 El área de explotación en torno al campamento de Posesión consideró aproximadamente 1.000 km2 en territorio continental, además de $2.500 \mathrm{~km} 2$ correspondientes a la superficie bajo el lecho marino del proyecto Costa Afuera. 


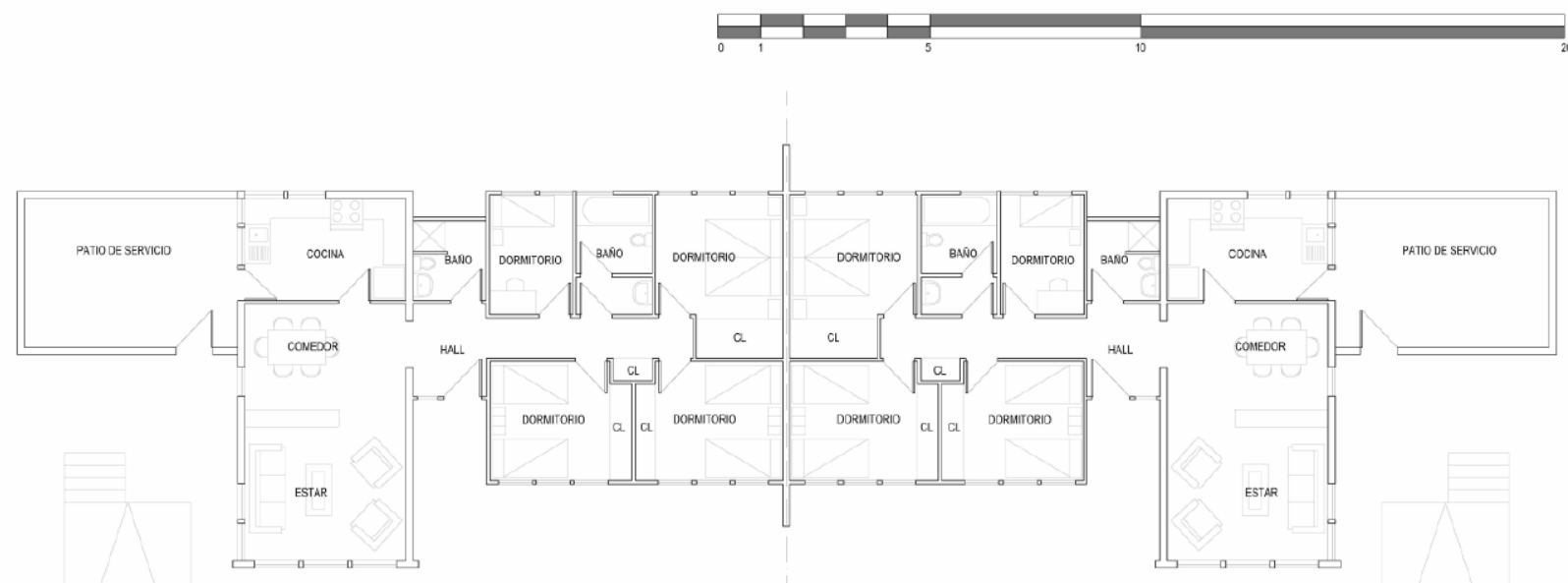

PLANTA ARQUITECTURA

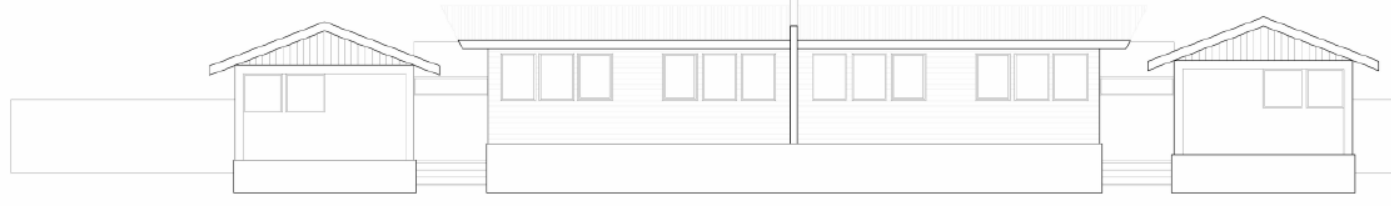

ELEVACIÓN POSTERIOR

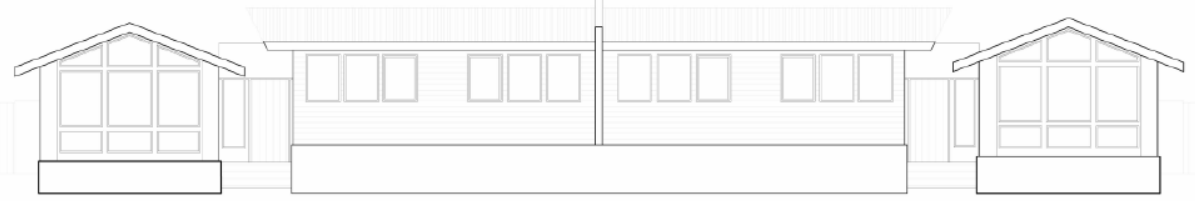

ELEVACIÓN PRINCIPAL

Fig. 18. Propuestas de viviendas para empleados, campamento de Posesión. Fuente: DOM (1978). Dibujo: Carolina Márquez C.

como de empleados, fueron construidas en base a módulos transportables prefabricados de madera, similares a los utilizados en los pabellones de obreros del campamento de Cerro Sombrero. Por su parte, las viviendas de la década de 1970 obedecieron a diseños diferenciados de las experiencias anteriores, principalmente en términos de superficie y expresión formal. Elaborados por el estudiante de arquitectura Danilo Fernández R., bajo la supervisión de la arquitecta Flor Vera L., consideraron en una superficie de $93 \mathrm{~m}^{2}$ un recinto de estar-comedor, un dormitorio principal, dos dormitorios dobles, un dormitorio individual, dos baños, una cocina y patio de servicio ${ }^{14}$ (Fig. 18).

14 Según Hecht (2002), el campamento consideraba sesenta y tres viviendas, con una capacidad de cuatrocientos cincuenta trabajadores. 


\section{CONCLUSIONES}

Siguiendo a Claire Étienne-Steiner, durante la segunda mitad del siglo XX, en las consideraciones respecto al debate sobre la cuestión patrimonial y el estudio de lo susceptible de considerarse como patrimonio arquitectónico, se produjo un giro relevante y radical. Se trató, según la autora, de una variación que consistió en abandonar el enfoque monográfico en la comprensión de la edificación en beneficio de una apreciación "global del territorio y al análisis de las relaciones de las obras entre ellas y con su territorio"15 (2003, p. 154). Aplicada al patrimonio industrial, la relación entre obra y territorio no puede entenderse de manera limitada a un espacio geográfico que actúa o actuó como soporte de una o varias industrias, sino como un entramado de mayor complejidad que trasciende al sitio y a los elementos específicos de la producción al "aplicarse también a todas las infraestructuras sociales, económicas, culturales o deportivas edificadas en el marco de una actividad productiva para asegurar las condiciones de vida de asalariados, a las colecciones de objetos científicos y técnicos constituidas y a los paisajes" (Hachez-Leroy, 2017, p. 6).

Si la arqueología industrial, entendida como "el estudio de una actividad de fabricación en un sitio" (Woronoff, 1989, p. 448), permitió ampliar los enfoques disciplinares y desarrollar una mirada más atenta a las industrias y sus instalaciones productivas y anexas, la penetración y variación del concepto de patrimonio industrial permitió valorar edificios e infraestructuras capaces de testimoniar sus singularidades y excepcionalidades a partir de sus territorios de implantación y ponderar los aportes de los grupos sociales que le dieron todo su sentido por las formas particulares que tomó la relación entre capital y trabajo.

Bajo estas premisas, el estudio y la comprensión de la vivienda juega un rol fundamental, no sólo por constituir un elemento configurador de paisaje industrial y contribuir a modelar el espacio geográfico, sino sobre todo por articular el espacio de la residencia y el espacio del trabajo, siendo parte del mismo territorio de producción, y en consecuencia, de relación, de interacción y reproducción social.

En los territorios de producción, por la sola magnitud de la mano de obra movilizada, no es posible entender la vivienda como un objeto aislado, sino necesariamente como parte de un hábitat colectivo que emergió de lógicas industriales precisas en momentos determinados y que es posible identificar y valorar. Así, la singularidad del hábitat colectivo asociado a la industria petrolera de la región de Magallanes se reconoce por el espacio geográfico donde se implantó, localizado en la sección occidental del territorio magallánico; por el período histórico que abarcó, tardío en relación a la explotación de los hidrocarburos allende los Andes; por la dimensión social que acompañó a la actividad productiva, y que permitió la constitución de una comunidad específica, autodenominada enapina; y por el modo de producción de viviendas.

15 Traducción de: “D’une approche monographique de l'œuvre on passe à une approche globale du territoire et à l'analyse des relations des œuvres entre elles et avec ce territoire” (Étienne-Steiner, 2003, p. 154). 
La organización espacial de ese hábitat colectivo no quedó determinada por la ubicación preferencial que pudieron tener las viviendas en función de la calidad de su diseño. Sin embargo, en la organización del espacio urbano es posible reconocer una segregación basada en las diferentes categorías socioprofesionales de la ENAP, en particular, empleados, obreros y, eventualmente, choferes y directivos. A ello deben agregarse la existencia de viviendas y grupos de viviendas emplazados y construidos en base a una diferenciación entre solteros y trabajadores con familias.

Respecto al modo de producción de las viviendas, en primer lugar, es posible partir de la idea que, en ningún caso, recibieron la atención cuidada que sí tuvo el diseño de los equipamientos colectivos construidos por la ENAP, pese a ser indispensables para fijar en los territorios de explotación una mano de obra especializada, inexistente en un área carente de centros poblados, y a sus familias. Efectivamente, los equipamientos colectivos de los campamentos de Cerro Sombrero (iglesia, gimnasio-piscina, cine y cooperativa), Cullen (iglesia y gimnasio) y, en menor medida, del campamento de Percy (escuela-cine), son la expresión de una reflexión más intensa, e inscrita, en algunos casos, en los parámetros de la modernidad en Chile, como fue el caso de la casi totalidad de los equipamientos colectivos de Cerro Sombrero.

En segundo lugar, es posible concluir, que el modo de producción, en particular el diseño y la ejecución, de las viviendas de los campamentos del petróleo en Magallanes fueron parte de un proceso constante de reformulación que transcurrió a lo largo de un período donde pueden identificarse con claridad tres etapas asociadas a diferentes estrategias de parte de la empresa estatal. Una primera etapa caracterizada por las propuestas confeccionadas por la Sección de Arquitectura de la ENAP, donde se elaboraron los diseños específicos para cada uno de los emplazamientos, como fueron los casos de Clarencia, Manantiales, Percy y Cerro Sombrero. Una segunda etapa, caracterizada por la sistematizaron de diseños en base a respuestas estandarizadas propuestas por los mismos profesionales de la empresa estatal, en función de la superficie de la vivienda, o soluciones prefabricadas en base a módulos, situándose en este escenario las viviendas de los campamentos de Cullen, Gregorio y Posesión. Finalmente, una tercera etapa, durante la década de 1970, caracterizada por la combinación de las soluciones preconizadas anteriormente, y que se evidencia a través de un retorno a los diseños específicos, esta vez exclusivamente para personal directivo, mientras se recurre a respuestas estandarizadas para obreros y empleados, ambas soluciones desarrolladas para el campamento de Posesión.

Abordada también en una dimensión histórica, la vivienda de los campamentos del petróleo también sufrió alteraciones, al diseñarse en función de la diversidad de los grupos familiares que hubo que alojar, forma de reconocimiento por parte de la empresa a las dinámicas sociales y estructuras familiares cambiantes a lo largo de los años. Hemos demostrado al respecto que la vivienda en los campamentos primeros, de Clarencia y Percy, se gestionó como una respuesta singular y un modelo único, variando posteriormente a una 
gestión más sofisticada que permitió variaciones en términos de superficie y número de recintos diseñados. Así, hemos constatado variaciones en la cantidad de dormitorios en las viviendas, de servicios anexos como despensa y lavadero, así como también de la incorporación de un dormitorio de servicio en las viviendas de empleados, de los campamentos de Cerro Sombrero, Cullen, Gregorio y Posesión.

Conviene detenerse respecto a la mutación de los espacios al interior de la vivienda, puesto que diversos autores han insistido en la dependencia que se produce entre la empresa y la totalidad de los residentes del campamento (Martinic, 2006; Garcés et al. 2007; Domínguez, 2011), una relación que hace del trabajador un habitante-obrero ${ }^{16}$, cuestión que resta visibilidad a otros residentes de los campamentos, como profesores contratados por cuenta del Estado y no por la ENAP directamente, por funcionarios públicos, por familiares allegados a los trabajadores o el personal del servicio doméstico, sujeto espacialmente inscrito en la domesticidad de la vivienda, incorporado como variable de diseño y a la vez inexistente en la sociabilidad del campamento.

Finalmente, debemos señalar que la vivienda de los campamentos del petróleo presenta un interés que trasciende sus atributos arquitectónicos, pues testimonia un modo de producción industrial y es evidencia de modos de vida, de relaciones sociales y de construcción de una memoria que perdura en la actualidad. El valor y la riqueza de los equipamientos y del conjunto no se sustenta sin la existencia, la documentación y la valorización de los espacios de residencia y de lo que se entendió en un momento de la historia como la base del sistema productivo: el trabajador y su familia, relación desdibujada y trastocada fuertemente desde la década de 1980.

\section{REFERENCIAS}

Acevedo, P., \& Rojas, C. (2014). Campamentos enapinos en Tierra del Fuego. Perspectivas desde el patrimonio industrial. Sophia Austral, 14, 85-97.

Acevedo, P., \& Rojas, C. (Eds.). (2015). Enapinos. Los Campamentos petroleros del fin del mundo. Un Patrimonio industrial por armar. Etapa fundacional (1945-1962). Santiago:

Consejo Nacional de la Cultura y las Artes.

Álvarez-Areces, M. Á. (2008). Patrimonio industrial. Un futuro para el pasado desde la visión europea. Apuntes, 21 (1), 6-25.

Babelon J. P., \& Chastel, A. (2013). La notion de patrimoine. Paris: Liana Levi.

Bergeron, L. (1995). Les villages ouvriers comme éléments du patrimoine de l'industrie.

16 Garcés et al. (2007) asimila el caso de Cerro Sombrero a una company town, siguiendo el modelo de los asentamientos de la industria minera del cobre en Chile. En esta relación se propone que a cada individuo del asentamiento, bajo una "estricta jerarquía social", se le dotaba de bienestar mientras era sujeto del control de la empresa, que "todo lo otorga y protege” (p. 30). En este sentido Domínguez (2011) manifiesta que el campamento "funciona como un centro fundamentalmente autónomo y cerrado, sirviendo sólo a quienes trabajan en la empresa" (p. 37). 
Recuperado de https://www.icomos.org/en/116-english-categories/resources/ publications/229-les-villages-ouvriers-comme-elements-du-patrimoine-de-lindustrie Brito, A., Cerda, G., Fuentes, P., \& Pérez, L. (Eds.) (2018). Industria y habitar colectivo. Conjuntos habitacionales en el sur de Chile. Concepción: STOQ Editorial.

Campamento movil Manantiales. (s.f.). [fotografía papel] archivo Ricardo Sandoval. Punta Arenas.

Chassagne, S. (2002). L'Elargissement d'un concept: de l'archéologie (industrielle) au patrimoine (industriel). Revue Le Mouvement Social, 1999, 7-9.

Choay, F. (2007). Alegoría del Patrimonio. Barcelona: Gustavo Gili.

Cvitanic, B., \& Matus, D. (2018). Industria y Hábitat colectivo en la Región de Magallanes: Dinámicas y singularidades de un modo de ocupación territorial, 1885-1971. Revista $180,42,36-48$.

Cvitanic, B., Matus, D., Ambrosetti, D., Herrera, R., \& Bustos, A. (2018). Hidrocarburos. En A. Brito, G. Cerda, P. Fuentes \& L. Pérez (Eds.), Industria y habitar colectivo. Conjuntos habitacionales en el sur de Chile. Concepción: STOQ Editorial.

Dirección de Obras Municipales (1978). Expediente No226. Posesión. I. Municipalidad de Punta Arenas.

Domínguez, P. (2011). Cerro Sombrero Arquitectura Moderna en Tierra del Fuego. Santiago: Consejo Nacional de la Cultura y las Artes.

Dorel-Ferré, G. (2008). Vivienda obrera y colonias industriales en la península Ibérica: actas de las Jornadas (2002) y del Congreso (2005) celebrados en el Museu de la Ciència i de la Tècnica de Catalunya. Terrassa: Museu de la Ciència i de la Tècnica de Catalunya.

ENAP (1951). Primera Memoria al 31 de diciembre de 1950. Santiago: ENAP.

ENAP (1952). Segunda Memoria Anual 1951. Santiago: Editorial Universitaria.

ENAP (1953). Memoria Anual 1952. Santiago: Empresa Editora Zig-Zag.

ENAP (1954). Memoria Anual 1953. Santiago: Empresa Editora Zig-Zag.

ENAP (1955a). Memoria Anual 1954. Santiago: Empresa Editora Zig-Zag.

ENAP (1955b). Plano A-S-23-2.

ENAP (1955c). Plano A-S-23-4.

ENAP (1955d). Plano A-S-23-4.

ENAP (1956a). Plano A-P-6-1.

ENAP (1956b). Plano A-P-7-1.

ENAP (1957). Plano ICO-S-55-8-18.

ENAP (1958). Memoria Anual 1957. Santiago: Empresa Editora Zig-Zag.

ENAP (1961a). Plano 2414-J-1006.

ENAP (1961b). Plano 2407-J-1006.

ENAP (1961c). Memoria Anual 1960. Labor de diez años. Santiago: ENAP

ENAP (1962). Plano 2464-e-1007.

ENAP (1966a). Plano ICO-S-37-1-1. 
ENAP (1966b). Plano IC BG 1018.

ENAP (1971). Memoria 1970. Santiago: Quimantú Ltda.

ENAP (1976). Memoria y Balance 1975. Santiago: Editora Nacional Gabriela Mistral.

ENAP (1981). Memoria y Balance 1980. Santiago: Editorial Antártica S.A.

ENAP (1982a). Memoria y Balances 1981. Santiago: Editorial Antártica S.A.

ENAP (1982b). Plano C-5A-53-82.

ENAP (1985a). Plano IPB-LT-1-26.

ENAP (1985b). Plano CL-2B-6-85.

ENAP (1987). Plano PP-1A-1-87.

ENAP (s.f.). Plano ICO-TC-11-1.

Étienne-Steiner, C. (2003). Du repérage au recensement: l'irruption du territoire. En H. Rousso Sous la présidence de (2003). Le regard de l'Histoire L'émergence et l'évolution de la notion de patrimoine au cours du XXe siècle en France. Paris: Fayard.

Fugellie, S. (1995). 50 Años de Comunidad Petrolera. Punta Arenas: Empresa Nacional del Petróleo.

Garcés, E., Cooper, M. \& Baros, M. (2007). Las ciudades del salitre. Santiago de Chile: Ediciones UC.

Garcés, E., Kroeger, F., Martinic, M., Piwonka, N., \& Cooper, M. (2013). Tierra del Fuego. Historia, Arquitectura y Territorio. Santiago, Chile: ARQ ediciones.

Hachez-Leroy, F. (2017). Un défi d'avenir: le patrimoine industriel. Revue Entreprise et Histoire, $87,5-13$.

Hecht, R. (2002). Trazado, paisaje y territorio: Cerro Sombrero y la arquitectura del petróleo en Magallanes. ARQ, 51, 64-67.

Hecht, R. (2005). Trazado, paisaje y territorio: Cerro Sombrero y la arquitectura del petróleo en Magallanes. Actas Patrimonio Moderno 1er Seminario DOCOMOMO CHILE.

Ibarra, M. (2015). Espacios de memoria. Cien años de Patrimonio Industrial en Chile (19152015). En P. Acevedo \& C. Rojas (Eds.), Enapinos. Los Campamentos petroleros del fin del mundo. Un Patrimonio industrial por armar. Etapa fundacional (1945-1962). Santiago: Consejo Nacional de la Cultura y las Artes.

Labadi, S. (2001). Industrial Archaeology as Historical Archaeology and Cultural Anthropology. Papers from the Institute of Archaeology, 12, 77-85.

Martinic, M. (1988). Magallanes 1921-1952: Inquietud y crisis. Punta Arenas: Ediciones La Prensa Austral.

Martinic, M. (2005 [1983]). Historia del Petróleo en Magallanes. Punta Arenas: Empresa Nacional del Petróleo.

Martinic, M. (2006). Historia de la Región Magallánica. Punta Arenas, Chile: Ediciones de la Universidad de Magallanes.

Martinic, M. (2009). La Tierra de los Fuegos. Historia, geografía, Sociedad, Economía. Punta Arenas, Chile: Ediciones La Prensa Austral. 
Matus, D., \& Cvitanic, B. (2016). La Empresa Nacional del Petróleo y la construcción de un paisaje urbano: Barrios de la ciudad de Punta Arenas. En G. Ciselli \& V. Navarro, V. (Eds.), Paisajes culturales y patrimonio: expresiones de la cultural territorial. Río Gallegos: Universidad Nacional de la Patagonia Austral.

Matus, D., \& Cvitanic, B. (2018). Oil and industrial heritage in Magallanes: urbanization, architecture and social construction (1945-1980). En J. Migone (Ed.), Patrimonio Industrial. Entendiendo el pasado, haciendo el futuro sostenible. TICCIH CHILE. Santiago: ER Impresores.

Merlin, P., \& Choay, F. (2005). Dictionnaire de l'urbanisme et de l'aménagement. Paris: Presses universitaires de France.

Ministerio de Educación (2014). Declara Monumento Nacional en la Categoría de Zona Típica o Pintoresca al "Campamento Cerro Sombrero" y Monumento Nacional en la Categoría de Monumento Histórico al "Equipamiento de Cerro Sombrero: Centro Cívico y Surtidor de gasolina de Cerro Sombrero”, ubicados en la Comuna de Primavera, Provincia de Tierra del Fuego, Región de Magallanes y de la Antártica Chilena. Recuperado de https://www. leychile.cl/N?i=1070667\&f=2017-10-16\&p

Pardo, Carlos (2016). El patrimonio industrial en España. Paisajes, lugares y elementos singulares. Madrid: Akal.

Pizzi, M., Valenzuela, M. P., \& Benavides, J. (2009). El patrimonio arquitectónico industrial en torno al ex Ferrocarril de Circunvalación de Santiago. Testimonio del desarrollo industrial manufacturero en el siglo XX. Santiago: Editorial Universitaria.

Puga, C. (1991). Plataformas Petroleras Arquitecturas del Mar. Revista Colegio de Arquitectos, 64, 63-66.

Strabucchi, W. (1994). 1984-1994 Cien Años de Arquitectura en la Universidad Católica de Chile. Santiago: Ediciones ARQ.

TICCIH (2003). Carta de Nizhny Tagil sobre el Patrimonio Industrial. Recuperado de https:// www.icomos.org/18thapril/2006/nizhny-tagil-charter-sp.pdf

Woronoff, D. (1989). L'archéologie industrielle en France: un nouveau chantier. Revue Histoire, économie et société, L'industrialisation, 3, 447-458. 